Portland State University

PDXScholar

\title{
Anthropogenic Noise and Cetacean Interactions in the 21st Century: a Contemporary Review of the Impacts of Environmental Noise Pollution on Cetacean Ecologies
}

Caitlin Gordon

Portland State University

Follow this and additional works at: https://pdxscholar.library.pdx.edu/honorstheses Let us know how access to this document benefits you.

\section{Recommended Citation}

Gordon, Caitlin, "Anthropogenic Noise and Cetacean Interactions in the 21st Century: a Contemporary Review of the Impacts of Environmental Noise Pollution on Cetacean Ecologies" (2018). University Honors Theses. Paper 625.

https://doi.org/10.15760/honors.636

This Thesis is brought to you for free and open access. It has been accepted for inclusion in University Honors Theses by an authorized administrator of PDXScholar. Please contact us if we can make this document more accessible: pdxscholar@pdx.edu. 
Anthropogenic Noise and Cetacean Interactions in the 21st Century:

A Contemporary Review of the Impacts of Environmental Noise Pollution on Cetacean Ecologies

by

Caitlin Gordon

An Undergraduate Honors Thesis submitted in partial fulfillment of the

requirements for the degree of

Bachelor of Science

in

University Honors

And

Biology

Thesis Adviser

Debbie Duffield, PhD

Portland State University 


\begin{abstract}
Anthropogenic noise has been identified as an environmental pollutant since the early 70 s and has since been shown to disrupt biologically significant functions of marine life. Recognizing that the world's oceans are undergoing unprecedented change in the $21^{\text {st }}$ Century, this study reviews the most current research related to the interactions between cetaceans and anthropogenic noise in their environment. Working with literature published after 2008, this review contextualizes the direct and indirect impacts of the greatest sources of anthropogenic noise: vessel traffic, seismic seafloor exploration, and sonar, and their effect on cetacean biology and ecology. This review found that vessel noise interferes with the communication and acoustic functions of cetaceans, as well as elicits behavioral responses that disrupt foraging activity and may contribute to the displacement of individuals and populations. Interactions between cetaceans and seismic surveys are similar to those described for vessel noise, with additional risks of temporary or permanent hearing loss due the intensity of the sounds produced. Sonar activities have greater impacts on the acoustic functions of toothed whales, impacting their ability to echolocate, and has been implicated in multiple mass strandings. In cases of mass strandings of deep-diving species, such as beaked whales, decompression sickness is implicated as a potential cause of death and recent studies of North Atlantic right whales have shown that increased environmental noise correlates with increased glucocorticoid stress hormone levels, suggesting that anthropogenic noise has a potentially injurious impact on cetacean physiology.
\end{abstract}

Keywords: marine mammals, cetaceans, anthropogenic noise, vessel traffic, seismic, sonar, noise 


\section{Table of Contents}

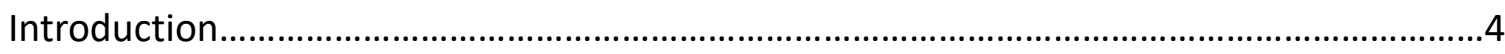

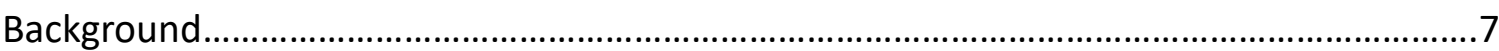

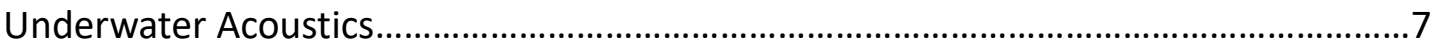

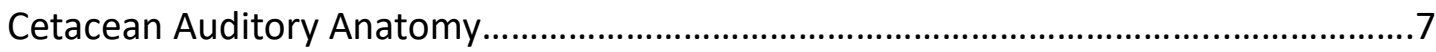

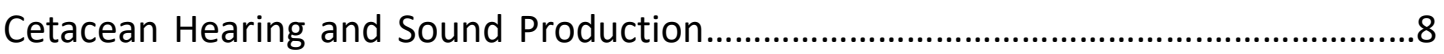

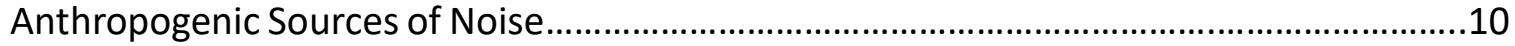

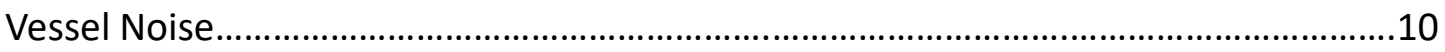

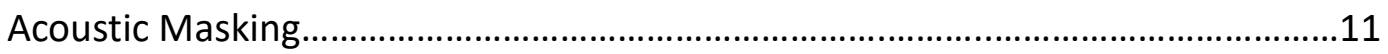

Deep-Ocean Sound Channels and the Arctic............................................................13

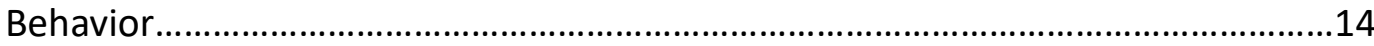

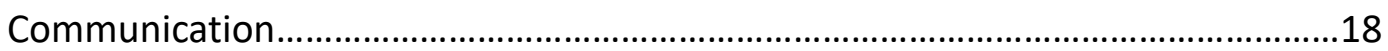

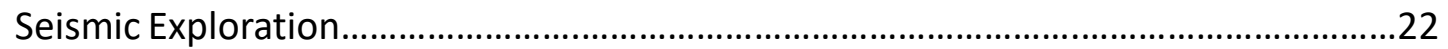

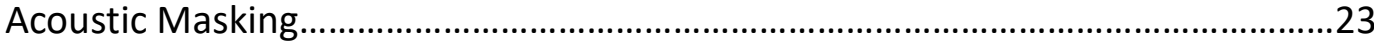

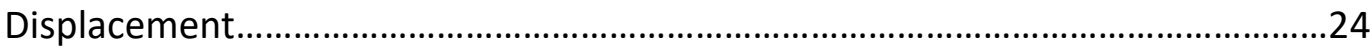

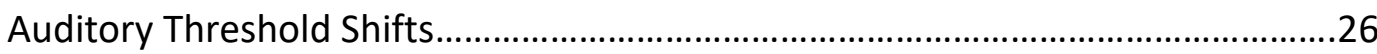

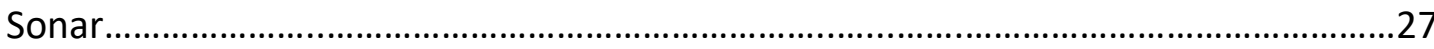

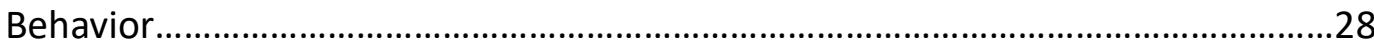

Deep-Diving Cetaceans and Decompression Sickness.............................................31

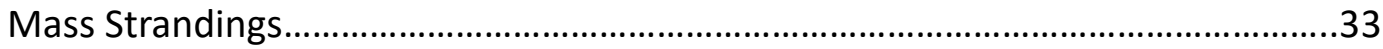

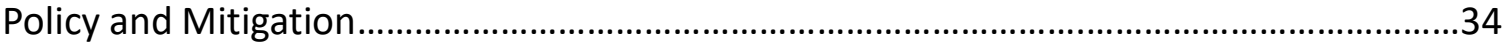

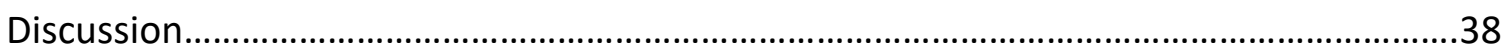

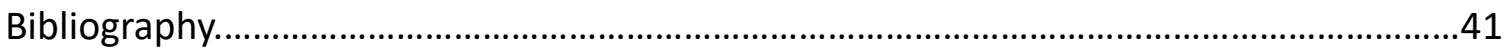

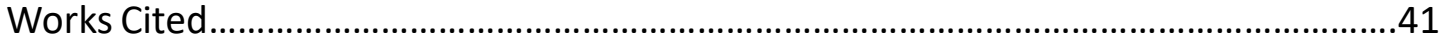

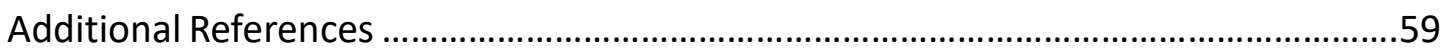




\section{Introduction}

North Atlantic right whales made headline news in February of 2018 when it was reported that no new calves were sighted following the end of their breeding season (Weintraub, 2018). Since 2010, calving rates for this species have declined upwards of $40 \%$ (Kraus et al., 2016), and on the heels of a mass mortality event in 2017 (NRC, 2018), the recovery of this critically endangered species is uncertain (Kraus et al., 2016; Meyer-Gutbrod \& Greene, 2018). The impacts of human disturbance in North Atlantic right whale habitats are profoundly visible, with the overwhelming majority of individuals bearing scars from ship strikes and fishing gear entanglements, and with human interactions implicated in over half of all right whale deaths (MMC, 2018). Research exploring the agents of population decline has highlighted evidence of chronic physiological stress in these animals (Hunt et al., 2017) and observable changes to their baseline behavior in response to environmental stressors, which may have exacerbated population displacement and decline (Hatch et al., 2012). Among the many factors contributing to the degradation of their habitats, human-generated noise has been identified as an invasive element with the capacity to disrupt the biologically significant functions of North Atlantic right whales (Hatch et al., 2012; Rolland et al., 2012).

Anthropogenic noise in the oceans was first recognized as an environmental pollutant in marine ecosystems in a study by Payne and Webb (1971), which described the capacity for long-range communication in baleen whales. The authors modeled the acoustic properties of fin whale calls and found that the low-frequency sounds generated by the whales were capable of propagating over vast distances and across ocean basins. As solitary animals with substantial geographic ranges, long-range communication between conspecifics may be a significant 
component of individual fitness, informing migratory, foraging, and reproductive behaviors. In modeling the acoustic propagation of the fin whale calls, the authors found that the lowfrequency sounds were susceptible to interference by ambient noise, and in habitats with significant vessel traffic, the maximum detectable range of low-frequency sounds could be reduced by thousands of nautical miles. With this foundational study, Payne and Webb presented the first evidence of anthropogenic noise impacting marine biology and ecology (Clark et al., 2009). At the time, underwater acoustic research was the exclusive realm of engineers and physicists, and minimal academic attention was given to the effect of noise on ecosystems until the 1990s (Williams et al., 2015). However, anthropogenic noise research has grown rapidly, driven largely by conservation efforts on behalf of marine mammals (Simmonds et al., 2014). Resolutions passed in the 2000s by the International Whaling Commission (IWC), the US Marine Mammal Commission (MMC), the International Maritime Organization (IMO), among others, have instituted programs and policies to address the negative impacts of human disturbance on cetaceans, resulting in a surge of research publications over the last 15 years (Simmonds, et al., 2014). Since 2010, the context of anthropogenic noise research has been largely ecological, with more than half of the publications considering impacts to one or more taxonomic group, contributing a wealth of new data on species, populations, and habitats (Simmonds, et al., 2014).

In the face of anthropogenic climate change, many cetacean habitats are rapidly degrading (Simmonds, et al., 2014; Williams et al., 2015). Reducing the degree to which human noise pollution contributes to that degradation is now recognized as an important consideration for future marine mammal research and conservation (Simmonds, et al., 2014; 
Williams et al., 2015; Ritts, 2017). Effective conservation strategies are challenged by the dearth of species-level data pertaining to cetacean biology and ecology (Parsons et al., 2009). Furthermore, the insular nature of scientific publishing has contributed to a lack of cohesion among marine science disciplines and restricted the access of knowledge to the general public, significantly limiting the potential for comprehensive policymaking (Williams et al., 2015). To inform the appropriate policies for cetacean conservation, a holistic, multivariate lens is necessary to contextualize the cumulative and interrelated effects of anthropogenic noise on cetacean ecology, physiology, and behavior (Clark et al., 2009; Ashe et al., 2010; Simmonds, et al., 2014; Williams et al., 2015).

The aim of this thesis is to provide an interdisciplinary review of literature that examines the myriad of effects of noise pollution on whales. Among the various sources of humangenerated noise in the world's oceans, of significant concern are sound emissions from oceanic vessels, seismic exploration of the seafloor, and sonar activities (Hildebrand, 2009; Simmonds, et al., 2014). This review presents research and literature that examines the direct and indirect impacts of these primary sources of anthropogenic noise, to understand how various cetacean species and populations cope with acoustic disturbance in their environment. This is not intended to be a comprehensive analysis of anthropogenic noise as an environmental pollutant, but rather a confluence of research from various disciplines and perspectives which frame a broad understanding of the multivariate interactions between human-generated noise and cetaceans. This review is limited to literature published after 2008 , coincident with the expansion of marine acoustic research noted in the mid-2000s (Williams, et al., 2015). 


\section{Background}

\section{Underwater Acoustics}

Having evolved from terrestrial mammalian ancestors prior to their return to the sea, cetaceans faced extraordinary challenges in adapting their auditory anatomy, designed to perceive sound through air, to function underwater (Ketten, 1992; Wartzok \& Ketten, 1999). Compared to propagation in air, underwater soundwaves demonstrate significantly less attenuation and slower energy loss, permitting considerably greater detectable temporal and spatial ranges (Wartzok \& Ketten, 1999). However, the increased density of liquid media requires far greater source-level production of sounds, upwards of $60 x$ louder than would be required in air (Wartzok \& Ketten, 1999). The magnitude of transmission loss and absorption of a soundwave in water is directly proportional to the magnitude of its energy, or frequency, therefore lower-frequency sounds demonstrate relatively enhanced propagation through water and have the capacity to broadcast for thousands of kilometers with little energy loss (NRC, 2000).

\section{Cetacean Auditory Anatomy}

Cetacean auditory adaptations have included the reduction of some bony, air-filled cavities and the loss of external pinnae, ostensibly in response to atmospheric pressure dynamics in ocean habitats (Ketten, 2002). Furthermore, cetacean ears display near-complete dissociation from the cranium, limiting the potential for bone conduction of acoustic waves (Ketten, 2002). Cranial morphology in cetaceans represent the greatest degree of modification observed in vertebrates, allowing for the development of acoustically important structures, soft 
tissues, and sinuses for the production and reception of sound underwater (Ketten, 1992;

Ketten, 2002). Modification of mysticete (baleen whales) ears show morphological adaptations driven primarily by size and scaling. However, the auditory structures in odontocetes (toothed whales) demonstrate significant modification in the mechanistic pathway of sound reception (Wartzok \& Ketten, 1999). In contrast to the typical mammalian ear, to which sound is channeled through external auditory canals, evidence suggests that odontocetes receive sound primarily through their lower jaws (Ketten, 1997). The posterior end of the mandible of a toothed whale is thin-walled and relatively flexible, housing thick pads of specialized acoustic fats. These lipid structures contain uncommon wax esters and long straight-chain fatty acids, through which sound can travel faster, and are believed to amplify and channel the acoustic vibrations directly to the inner ear (Wartzok \& Ketten, 1999; Koopman et al., 2006). Special fats are also found in the melon of odontocetes, serving as the foundation for echolocation - an acoustic function critical to the predatory and social functions of toothed whales (Ketten, 1992). The auditory bullae in odontocetes are significantly thicker and denser than any other mammal, with the near-complete lack of bony associations with the cranium, serving to further isolate the auditory complex from exogenous acoustic waves and preferentially conduct sound through their highly modified auditory structures (Ketten, 1992).

\section{Cetacean Hearing and Sound Production}

There is little empirical data regarding the functional hearing ranges in most cetacean species (NRC, 2003) and inferences regarding their auditory sensitivities have often been based on the characteristics of the sounds they produce (Wartzok \& Ketten, 1999). Limited 
audiometric data from some odontocete species indicate that these whales have functional hearing ranges between $150 \mathrm{~Hz}$ and $180 \mathrm{kHz}$, with upper-quartile ranges potentially extending to $200 \mathrm{kHz}$ (NRC, 2003; NOAA, 2014). There have been no direct measurements regarding mysticete hearing ranges, however audiometric models suggest median auditory capacities within $20 \mathrm{~Hz}$, with substantial representation throughout low- and mid-frequency acoustic bands below $1 \mathrm{kHz}$, with upper quartile hearing ranges possibly extending to $30 \mathrm{kHz}$ (NRC, 2000; NRC, 2003; NOAA, 2014). Odontocetes produce a broad spectrum of ultrasonic sound types and frequencies, categorized by peak spectra above $100 \mathrm{kHz}$ (Type I) or below $80 \mathrm{kHz}$ (Type II) (Wartzok \& Ketten, 1999). Type I species are typically found in nearshore habitats with significant acoustic interference by bathymetric or biotic components, producing sounds up to $200 \mathrm{kHz}$. Type II species are more typical of open ocean habitats, producing lower-frequency sounds between 30 and $80 \mathrm{kHz}$, which have relatively greater detection ranges (Kamminga, 1988; Wartzok \& Ketten, 1999). Species of this type devote a significant proportion of their acoustic energy to conspecific communication (Wartzok \& Ketten, 1999). All cetacean species demonstrate preference for distinct frequency bands, suggesting that different groups may segregate acoustically to reduce communication interference (Clark et al., 2009).

As the energy of acoustic waves will diminish spatially, the thresholds at which cetaceans perceive sounds will vary depending on whether the sounds are impulsive or continuous (NOAA, 2018a). Continuous noise present in sound pressure levels above $120 \mathrm{~dB}$ will elicit a behavioral response while responses to impulsive noise occur at levels greater than $160 \mathrm{~dB}$. Cumulative sound energy of continuous noise can elicit permanent hearing threshold shifts between $173 \mathrm{~dB}$ and $199 \mathrm{~dB}$, for high-frequency and low-frequency cetacean species, 
respectively (NOAA, 2018a). Type I odontocetes experience the onset of permanent threshold shifts at sound pressure levels between 155 and 202 dB; Type II species begin to lose their hearing at levels between 185 and $230 \mathrm{~dB}$. Low-frequency mysticetes species demonstrate permanent threshold shifts with impulsive noise intensities between 183 and $219 \mathrm{~dB}$ (NOAA, 2018a). These values are dependent on whether the impulsive noise source is singular or the accumulation of multiple sources, in addition to other regional and species-level interactions.

\section{Anthropogenic Sources of Noise}

\section{Vessel Noise}

Oceanic vessels are an abundant and ubiquitous source of broadband-frequency noise in the oceans, with propulsion comprising the majority of sound emissions (Mitson, 1995; Hildebrand, 2009; Wittekind \& Schuster, 2016). Mechanical noise from engines, propellers, and gearboxes produce a significant proportion of the low-frequency sound emissions between $1 \mathrm{~Hz}$ and $1 \mathrm{kHz}$, while sound resonance through interactions with a ship's hull can further intensify internal mechanical noise (Mitson, 1995; Hildebrand, 2009). Mid- and high-frequency sound emissions from vessels are largely attributable to propeller "cavitation" (Wittekind \& Schuster, 2016). As the propeller blade spins, the acceleration of the surrounding fluid creates a pressure differential on either side of the blade tip. The formation of a negative pressure system on one side of the propeller blade forces dissolved gases out of the solution, forming bubbles along the blade edge. When introduced to the higher-pressure system on the other side of the blade, the bubbles rapidly collapse, each producing a low-energy shock wave that emits a low-frequency sound (Moholkar \& Pandit, 2004). The rate of bubble formation increases with vessel speed, 
which has a cumulative effect of increasing the total frequency range and decibel levels of the sounds emitted (Hildebrand, 2009; Wittekind \& Schuster, 2016). In terms of sound pressure, the various sources of noise on vessels contribute to decibel levels ranging from 140 to $200 \mathrm{~dB}$ (NRC, 2003; Hildebrand, 2009). The total sound emission from an individual ship is highly variable with regard to speed, activity, load weight, and mechanical components, however there is a direct correlation between ship size and magnitude of sound generated (Mitson, 1995; NRC, 2003; Hildebrand, 2009). Due to the prevalence of oceanic vessel traffic, and the enhanced propagation of low-frequency sounds in water, it is believed that vessel noise constitutes a significant proportion of ambient noise in the world's oceans (NRC, 2003; Hildebrand, 2009).

\section{Acoustic Masking}

Clark et al. (2009) adapted the theory of acoustic masking, a phenomenon well-studied in vocal terrestrial animals, for marine mammal ecosystems. The authors suggested that oceanic vessels contribute continuous low-frequency noise, acoustically capable of dominating and persisting across a range of frequency bands at considerable distances, interfering with the transmission of biologically significantly calls between conspecifics. With a focus on the lowfrequency sound interactions between mysticetes and ocean vessels, Clark et al. (2009) investigated vessel noise interference within cetacean communication spaces. Communication spaces were defined as the geographic range within which cetacean conspecifics can hear and be heard by one another, perceive self-produced bioacoustic signals (e.g. echolocation), and receive exogenous signals regarding predators, prey, and bathymetric information. The authors modeled the communication spaces of right whales, fin whales, and humpback whales, based 
on their respective use of different frequency bands and the predicted noise contributed by passing ships. The models demonstrated interference across all sample species to some degree, however it was suggested that only one ship traveling through right whale territories could impact $97 \%$ of their bioacoustic signaling space within $20 \mathrm{~km}$. The authors' findings suggested that vessel noise interference diminishes an individual whale's ability to spatially and acoustically differentiate bioacoustic signals from noise. As each vessel has its own distinct acoustic signature, the cumulative effect of multiple vessels can impact and dominate frequency bands of multiple species within a region. Clark et al. (2009) concluded that such acoustic disturbance in cetacean habitats has the capacity to significantly mask the transmission of biologically significant information between conspecifics with potential negative impacts on foraging, reproduction, and migration.

Jensen et al. (2009), investigated the broadband impacts of vessel noise on the communication space of delphinids. This study used remote digital acoustic recording tags deployed in a population of short-finned pilot whales in the open ocean near the Canary Islands. Additionally, the authors collected audiometric data from hydrophones in Koombana Bay, Australia, an important coastal habitat for bottlenose dolphins, to compare the propagation of vessel noise in deep and shallow marine environments. Acoustic sequences obtained from the pilot whale study showed that passing vessels contributed an additional 20 $\mathrm{dB}$ to ambient noise levels over frequency bands commonly used for communication. Hydrophones in the dolphin habitat recorded background vessel noise in frequencies exceeding $1 \mathrm{kHz}$, well within odontocete hearing and vocal frequencies. Jensen et al. (2009) suggested that the acoustic masking potential for broadband noise radiating from vessels may have 
considerable impacts on delphinid acoustic signaling, critical for echolocation and conspecific communication, diminishing their communication space by upwards of $26 \%$. A case study by Bassett et al. (2012) measured the ambient noise levels within the Admiralty Inlet of Washington State's Puget Sound, a primary habitat for gray whales, harbor porpoises, and endangered Southern Resident killer whales. The authors presented evidence suggesting that $79 \%$ of the acoustic energy present in the ecosystem was due to cargo vessels, finding that vessel noise was a continuous and persistent component of the acoustic profile of the Admiralty Inlet, with vessels present for $90 \%$ of the study period and $68 \%$ of samples containing emissions from two or more ships.

\section{Deep-ocean Sound Channels and the Arctic}

A detailed acoustic description of the most significant sources of anthropogenic noise by Hildebrand (2009) identified shipping noise as a disruptive variable in all marine environments. The author's review of acoustic propagation revealed that vessels moving over continental slopes broadcast their noise downward, where it can enter deep-ocean sound channels. These channels interact with surface waters near the poles and are the primary pathways for longrange propagation of bioacoustic signals by mysticetes whales. Because of this, Hildebrand suggested that low-frequency vessel noise has the capacity to persist across ocean basins and interfere with cetacean bioacoustics thousands of kilometers from its source.

The interactions between deep-ocean sound channels and persistent propagation of low-frequency noise in shallow waters has been implicated as an ecological concern for Arctic species, which are particularly vulnerable to climate change impacts in their environment 
(Gervaise et al., 2012; Moore et al., 2012a; Moore et al., 2012b). In a case study of belugas in the northeastern Canadian fjords, authors Gervaise et al. (2012) determined that passing vessels added 30 to $35 \mathrm{~dB}$ to ambient noise levels, masking frequencies coincident with beluga echolocation and contributing to a loss of up to $30 \%$ of their communication space (Gervaise et al., 2012). Reduced sea ice coverage has been correlated with increased vessel traffic in the Arctic, necessitating new approaches in the management of vessel noise in this shallow ocean (Moore et al, 2012a). In addition to belugas, the Arctic Ocean is the year-round home for bowhead whales and narwhals. For these whales, the projected increases in shipping traffic and hydrocarbon prospecting are predicted to significantly interfere with important foraging and nursery habitats (Moore et al., 2012b; Reeves et al., 2014; Small et al., 2017). Belugas and narwhals are listed by the International Union for the Conservation of Nature (IUCN) as Near Threatened, some bowhead subpopulations listed as Critically Endangered, and all three species are particularly sensitive to habitat degradation (Moore et al., 2012b; Norman et al., 2015).

\section{Behavior}

Empirically assessing behavioral responses on free-swimming marine mammals is exceptionally difficult, and significant challenges exist in quantifying such responses (Lusseau et al., 2009; Stamation et al., 2010). In response to anthropogenic noise, baseline observations of negative stimulus response are typically centered around avoidance of said stimulus (La Manna et al., 2013). Nonetheless, as more studies emerge about subtle changes in cetacean behavior, observations of disturbance responses have been adapted to include any alteration in 
contemporaneous behavior (La Manna et al., 2013). Dyndo et al. (2015) observed "porpoising" behavior, or cycles of diving and leaping out of the water in short continuous intervals, in harbor porpoises penned near active shipping lanes. The authors reported that the captive porpoises reacted to over $30 \%$ of the boats recorded near the study site, abandoning their activities and engaging in near-synchronous "porpoising", implying an increase in energetic costs. The sounds recorded were not significantly loud in terms of decibel level, however the statistical analysis implied that sources levels as low as $123 \mathrm{~dB}$ have the potential to elicit minor response behaviors. Furthermore, the authors suggested that harbor porpoises in more heavilytrafficked will experience a greater magnitude of high-frequency vessel noise due to the enhanced propagation of sound in shallow waters.

Deep-diving cetacean species pose even greater challenges to behavioral observation, due to their limited surface activities. Beaked whales are among the most speciose of cetacean families, constituting $21 \%$ of cetacean species (Moore \& Barlow, 2013). Very little is known about beaked whale ecologies, however they are some of the most visible victims of human disturbance. Deep-ocean propagation of low-frequency vessel noise has the capacity to interact with the habitats of these whales, known to feed at depths below 1000m. Pirotta et al. (2012) utilized a bottom-mounted array of hydrophones to track several groups of Blainville's beaked whales in the Bahamas. The array, installed for military use, contained over 80 individual hydrophones in clustered groups and peripheral units, some separated by thousands of meters, allowing for the spatial detection of individual echolocating whales. By observing the number of changes in the primary hydrophone of detection, indicating movement through the study space, the authors determined that vessel noise exposure elicited significant changes in 
swimming behaviors, suggesting avoidance, with a correlation between the magnitude of movement and relative distance of source vessel. Conservatively speaking, Pirotta et al. (2012) suggested that low-frequency vessel noise capable of eliciting a significant response by Blainville's beaked whales would be detectable within $5.2 \mathrm{~km}$. While the behavior changes noted by the authors may be minor, these animals expend tremendous energy to forage in deep waters and reduction in foraging efficiency due to vessel noise could have detrimental effects to their energy budgets

For many coastal cetaceans, vessel traffic has been a permanent element of their ecosystem for a very long time. Limited habituation to vessel noise has been demonstrated in humpback whales residing in close proximity to persistent whale-watching vessels (Stamation et al., 2010), and many studies suggest that most behavioral responses to vessel noise are minor (La Manna et al., 2013). Bottlenose dolphins near the Sicilian island of Lampedusa, are exposed to significant shipping traffic. La Manna et al. (2013) recorded continuous samples of vessel traffic in this dolphin habitat, comparing noise levels to the degree of acoustic activities from the dolphins. The authors found a limited, but significant tolerance to increased boat noise in their environment, with roughly $98 \%$ of the recorded dolphin sounds occurring in the presence of boats. However, increasing source levels and prolonged persistence of vessel noise had a significant effect on dolphin presence, with only $1.98 \%$ of the recorded vocalizations occurring after periods of intense noise, which suggests that the dolphins were displaced from their primary territories for some time. The Lampedusa bottlenose dolphins live in a homogenous ecosystem with abundant energy resources and their numbers have increased significantly in the last few decades. The authors suggested that the stability of the ecosystem 
and abundance of high quality prey may have outweighed the risks of vessel noise disturbance, allowing for the population to adjust its communication and foraging strategies (La Manna et al., 2013).

The energetic effects of vessel noise on cetacean behavior can often be quantified by changes to foraging behavior. Foraging at depth is a careful balance of metabolic demands, oxygen reserves, and energy expenditure; any departure from normal foraging behavior is likely to have a negative effect on this energy budget (Pirotta et al., 2012). Humpback whales are cosmopolitan generalists, occupying nearly all epipelagic ecosystems, and in some cases are known to feed on benthic invertebrates in shallow waters (Blair et al., 2016). Well-known for their complex vocal behaviors, this previously endangered species has been the subject of significant study relative to anthropogenic noise. Authors Blair et al. (2016) observed the foraging patterns of benthic-feeding humpback whales and found that vessel noise exposure correlated with a decrease in depth dives and an increase in ascent behavior, indicating foraging cessation. These whales will dive down to the shelf bottom, where they will roll onto their sides and comb the seafloor for sand lice. When exposed to ship noise, however, the authors noted a $29 \%$ decrease in the number of side-rolls. Out of a total 218 dives recorded, 11 dives exhibited no side-rolling behavior, with seven of those dives occurring in the presence of vessel noise. Humpback whales are a highly adaptable species and have been known to habituate to various sources and magnitudes of human disturbance (Dunlop, 2016). With this understanding, Blair et al. (2016) suggested that the whales may have been more sensitive to disturbance because they are engaging in novel foraging behaviors or it may have been that the population studied had yet to habituate to local vessel noise. Due to the study being conducted 
on whales foraging at night, when vessel traffic is minimal, the authors suggest that their findings may be representative of baseline, unmediated responses to vessel noise disturbance for humpbacks.

Harbor porpoises have also been observed altering their foraging behaviors in response to vessel noise. Wiśniewska et al. (2018), surveyed the resident harbor porpoises of the shallow Danish coasts. Tagged with spatial-acoustic sensors, the porpoises were tracked during periods of low- and high-intensity vessel noise. The authors determined that all but one individual were exposed to high-frequency sounds likely to coincide with harbor porpoise hearing and echolocation. During periods of high-intensity vessel noise, some of the individuals believed to be foraging demonstrated a decrease in echolocative activity with subsequent reductions in the number of prey captured. Two porpoises of contrasting age and health, when exposed to a fastmoving and loud ferry, both demonstrated greater dive behaviors and swimming force, abandoned foraging behaviors, and dramatically diminished vocal activity. With respect to the harbor porpoises' energy budgets, Wiśniewska et al. (2018) noted that the loss of 15 minutes of foraging time could mean a loss of over 20 prey items. Without knowing the complex factors active within the population and ecosystem, the authors acknowledged the impossibility of determining the true impact of vessel noise on these animals but suggested that the implications of the data are likely to be underestimated.

\section{Communication}

Various publications have described the plasticity of communication behaviors demonstrated by cetaceans coping with increased vessel noise in their environment (Clark et 
al., 2009). Delphinids demonstrate a broad range of vocal capabilities which they use to forage, navigate, and strengthen communal bonds (Jensen et al., 2009). Building upon previous research in delphinid acoustic behavior relative to vessel noise (Jensen et al., 2009; La Manna et al., 2013), Papale et al. (2015) investigated acute shifts in frequency-band utilization under vessel noise exposure. Recording various calls from Atlantic spotted dolphins, short-beaked common dolphins, and striped dolphins around the Canary Islands, the authors found that all species modified their calls to compensate for passing ships. Vessel noise added between 20 and $120 \mathrm{dBs}$ to the delphinid habitats, with significant increases in sound pressure levels within the $4.4 \mathrm{kHz}$ to $11.2 \mathrm{kHz}$ frequency range utilized by all three species. When exposed to highdecibel vessel noise, Atlantic spotted and short-beaked common dolphins responded by extending the maximum frequency of their respective calls, while the striped dolphins extended their minimum frequency range. Although the dolphins demonstrated vocal plasticity, Papale et al. (2015) noted that sound production is largely constrained by anatomy and these cetaceans may be physically unable to compensate similarly with greater increases in noise levels.

The detrimental effect of vessel noise on delphinid communication has been extensively studied in Southern Resident killer whales. This critically endangered subpopulation occupies the heavily-trafficked waters of the Pacific Northwest United States and southern British Columbia, with considerable site fidelity (EPA, 2017). Comprised of three pods believed to segregated by matrilines, Southern Resident killer whale numbers have declined in the last three decades and as of December 2016, only 78 individuals remained in the territory they've occupied for over 5000 years (EPA, 2017). Lusseau et al. (2009) presented evidence for vessel noise disruption in Southern Resident killer whales and found that the whales would cease 
foraging in the presence of passing vessels and significantly increase their surface-active behaviors. Considering the exceptional degree and year-round persistence of vessel traffic from shipping and recreation, the authors suggested the whales' ability to echolocate has been significantly reduced, with specific impairment to peripheral prey detection. Killer whales are well-known for their extensive use of various call types, with many being distinct to subpopulations and pods (Holt et al., 2011). Many of these call types are dynamically modulated, having both low-frequency and high-frequency components relative to their function. Building on previous research suggesting that variations in stereotypical call types of Southern Resident killer whales were related to noise levels in their environment, authors Holt et al. (2011) characterized the acoustic profile of these whales in the noisy Salish Sea. In this study, increased source levels of noise correlated with changes in call amplitude of these whales, to the detriment of call types with high-frequency components which already require higher source levels under quieter conditions. High-frequency calls are the predominant call type in large Southern Resident killer whale aggregations. These call types are multidirectional and believed to be critical to group orientation and communication. In addition to increasing call amplitude, data analysis by Wieland et al. (2010) found that the overall duration of discrete killer whale call types had increased when compared to recordings made 28 years prior. The authors were able to rule out seasonal changes and maturation as agents of this shift and noted that recreational vessel traffic in killer whale habitats has increased tremendously since the 1990s, contributing to the coincident increase in noise levels. Veirs et al. (2016) found substantial emissions of high-frequency $(+10 \mathrm{kHz})$ noise from ships in the Salish Sea, which may potentially interfere with killer whale echolocation and foraging efficiency. Utilizing 
hydrophones, the authors noted that passing ships contributed up to 13 additional decibels to background noise in the 10 to $96 \mathrm{kHz}$ range, coinciding with the killer whales' typical frequency bands. Anthropogenic noise is just one of a few factors threatening the survival of Southern Resident killer whales, however with the consideration that their highly vocal social structures and group-specific "dialects" may be critical to cultural transmission (Deecke et al., 2010), management of noise in their home waters is necessary for their conservation (EPA, 2017). Like the Southern Resident killer whale, the critically endangered North Atlantic right whale faces significant threats to their survival because of vessel noise and has become the sentinel species for the impacts of anthropogenic noise in the oceans (Clark et al., 2009). The North Atlantic is a region of tremendous oceanic shipping traffic, in densities and speeds that correlate with the greatest degree of acoustic masking measured in cetacean habitats worldwide (Clark et al., 2009; Hildebrand, 2009). Hatch et al. (2012) used satellite vessel tracking to model the acoustic impact of vessel noise in the North Atlantic and suggested that right whales have lost 63 to $67 \%$ of their total communication space compared to pre-industrial conditions. Furthermore, North Atlantic right whales demonstrate lower source levels in their call types relative to other calling baleen whales in the region, further limiting their ability to compensate for increased noise levels. The authors suggested that the various low-frequency calls of these whales convey critical information to conspecifics regarding foraging opportunities, migration, and mate selection, and identified the magnitude of acoustic masking by vessel traffic as a likely contributor to species decline. In addition to communication loss, research on right whales has yielded evidence of physiological stress due to vessel noise. In the weeks following the events of September 11, 2001, virtually all shipping traffic in the North 
Atlantic has ceased, providing researchers with the unprecedented opportunity to study these animals under quiet conditions. During this time, Rolland et al. (2012) analyzed fecal and tissue samples of North Atlantic right whales for hormonal changes and found that the levels of glucocorticoid stress hormones had decreased significantly in line with the dramatic reduction in noise, falling well below the hypothesized baseline. The authors noted the difficulty in quantifying the effects of chronic physiological stress in whales, however they refer to extensive research implicating stress as detrimental to physical health and immunity, reproductive fitness, and species recruitment.

\section{Seismic Exploration}

What lies beneath the ocean floor is of great interest to scientific research and the fossil fuel industry (Hermannsen et al., 2015). Reflective seismology is used to categorize the geophysical structure of the seabed and can inform inferences about paleogeological conditions as well as reveal hydrocarbon reservoirs beneath the surface (Mooney \& Brocher, 2010). The process involves the use of airgun arrays that produce high volumes of highly pressurized air bubbles which emit soundwaves upon release. The soundwave will penetrate the seafloor and be reflected in portion by the different strata. Hydrophones receive the reflected sounds and analyze changes in sound pressures to generate a vertical map of the seafloor crust (Weglein et al., 2003). The seismic arrays consist of a dozen or more individual airguns firing sequentially in 10 to 20 second intervals, for upwards of 24 hours, over the course of weeks or months (Weilgart, 2007; Dunlop et al., 2017a). The airguns generate primarily low- and mid-frequency sound between 5 and $300 \mathrm{~Hz}$, however due to the cumulative effects of multiple sound sources 
in the same water mass, the total sound emissions from a seismic survey can occupy frequencies up to $22 \mathrm{kHz}$ (Weilgart, 2007; Weir \& Dolman, 2007). In order to penetrate the seafloor strata, the seismic arrays produce high-intensity sounds with source levels of 220 to $260 \mathrm{~dB}$ (Weilgart, 2007). The area of effect is dependent on the magnitude and duration of the seismic survey, however the sound produced by the array can dominate broadband frequencies and persist for many kilometers (Weir \& Dolman, 2007).

\section{Acoustic Masking}

In addition to their findings on vessel noise, Clark et al. (2009) considered the lowfrequency and broadband components of seismic airguns to have the same acoustic masking capacity as vessel noise. Recording blue whale calls during a seismic survey near the critical feeding grounds of the St. Lawrence Estuary, Canada, Di lorio and Clark (2009) found that seismic "sparkers" elicited an increase in call production and is the first evidence presented that describes changes in mysticete vocal behavior that go beyond cessation. Fin whales in the relatively shallow Mediterranean Sea, wherein they are exposed to significant airgun noise with high source levels, have also been observed modifying their call types and call durations in response to increased ambient noise (Castellote et al., 2012). Castellote et al. (2012) collected acoustic data during a 10-day seismic survey and observed airgun source levels upwards of 204 $\mathrm{dB}$ dominating across low-frequency bands, which contributed an additional $15.32 \mathrm{~dB}$ to total ambient noise levels, with a maximum additional $27.5 \mathrm{~dB}$ in fin whale communication frequencies. The authors found that fin whales compensated for the increased noise by decreasing the frequencies and durations of their calls, noting that the use of frequencies 
outside of their optimal range can impact individual energy costs. Although seismic activity is dominated by low-frequency sound emissions, the broadband components of airgun pulses have the capacity to interfere with odontocete communication as well. Hermannsen et al. (2015) modeled the propagation of individual airgun pulses in the shallow Arctic Ocean and found that they conserved much of their high-frequency acoustic energy, up to $10 \mathrm{kHz}$, due the insufficient physical space needed for significant energy loss. The authors determined that the pulse frequencies occupied the majority of frequencies that harbor porpoises use for conspecific communication, but did not suggest that the effects of these singular airgun pulses were injurious. They did note, however, that the sizable arrays used for large-scale seismic exploration have the capacity to produce sounds upwards of $260 \mathrm{~dB}$, contributing to acute, but substantial, increases in total ambient noise levels.

\section{Displacement}

Habituation to seismic activity, or even a lack of response, has been observed for some species due to regional mitigation strategies (Weir \& Dolman, 2007; Dunlop et al., 2015;

Dunlop, 2016; Winsor et al., 2017), yet many cetacean groups demonstrate some significant changes to their behavior when exposed to seismic noise. Weir (2008) made observations of humpback whales, sperm whales, and Atlantic spotted dolphins during a 10-month seismic survey off the coast of Angola. The survey used a large array of 24 airguns, with the capacity to produce significant volumes and source levels, but had implemented some of the mitigation strategies developed to limit wildlife impacts, such as "soft-start" and "ramp-up" procedures to warn nearby animals. Weir (2008) did not note any significant overt responses on behalf of 
humpback or sperm whales, but did note that the surface activities and boat interactions of the spotted dolphins ceased during the seismic period, with considerable avoidance distances. The author notes that the high-frequency components of the airgun pulses likely dominate the hearing ranges of spotted dolphins, with substantial acoustic energy in close range. Minor changes to diving and foraging behaviors are believed to incur costs to cetacean energy budgets (Pirotta et al., 2012). For humpback whales, seismic activity appears to have little effect on their general behaviors, however Dunlop et al. (2017b) noted that their migratory progression slowed down considerably, especially in larger aggregations, which could contribute to longterm displacement.

Narwhals are an elusive Arctic Ocean species, inhabiting the waters of Baffin Bay, a recent site of considerable seismic seafloor exploration (Heide-Jørgensen et al., 2013). Although not considered a threatened species, narwhals are particularly sensitive to human disturbance and typically respond by quickly diving and subsequently disappearing. Furthermore, narwhals have never been sighted at the surface from observers aboard seismic survey vessels. Narwhals are not particularly fast swimmers; it is believed that these whales evade perceived threats by entering the dense Arctic pack ice. Migration patterns for narwhals are spatially and temporally rigid, with high degrees of site-fidelity, therefore aberrant traveling behaviors are a concern for management and conservation. Heide-Jørgensen et al. (2013), speculated about the effect of local seismic activity from a few curious cases of narwhal ice entrapments between 2008 and 2010. In the autumn and winter of 2008 , seismic surveys were conducted for the first time in Baffin Bay during a critical migratory period when narwhals were moving southward through the region. In November of 2008, reports emerged of some thousands of narwhals traveling at 
relatively high speeds, inconsistent with their stereotypical migratory behaviors. When the seas had frozen for the winter, an estimated 1000 narwhals were found trapped at breathing holes, unable to reach open waters. Similar events in 2009 and 2010, coincident with seismic activity in Baffin Bay, resulted in 30 to 100 narwhals being trapped in frozen pack ice along the coastal margins. Harwood et al. (2010) noted that entrapments are not uncommon for high Arctic species like narwhals, however they typically occur within fast ice regions, where oceanographic forces create cracks and fissures that provide access to air and open water, which called into question these anomalous entrapment events. Due to the concurrence of the entrapments with regional seismic explorations, the authors speculated that they may be related.

\section{Auditory Threshold Shifts}

As a cosmopolitan coastal species, harbor porpoises often reside in noisy waters (Lucke et al., 2009). The intensity of seismic airgun noise, with source levels in excess of $250 \mathrm{~dB}$, has been shown to induce temporary threshold shifts in some odontocete species, with some observed permanent threshold shifts occurring with exposure to source levels of $230 \mathrm{~dB}$ in close ranges (Lucke et al., 2009). Lucke et al. (2009) measured auditory threshold shifts in an individual harbor porpoise, trained for scientific experiments, as they exposed it repeatedly to seismic airgun noise. The porpoise demonstrated the onset of temporary threshold shifts at source levels of $200 \mathrm{~dB}$ in the $4 \mathrm{kHz}$ frequency band, with a slower rate of recovery than expected, implying that the cumulative effect of repeated acute exposures may have longer lasting impacts. Kastelein et al. (2017) produced similar results by using an airgun of lesser 
volume. The authors noted a temporary threshold shift at $4 \mathrm{kHz}$ after 10 successive airgun trials averaging $188 \mathrm{~dB}$. Ethical constraints prevented both studies from exposing the animal to noise levels believed to be characteristic of full seismic arrays, and the authors noted that seismic noise in the field may have greater potential for hearing damage. Because seismic exploration uses low-frequency sounds to conserve acoustic energy, high-intensity airgun activities direct a greater amount of energy through frequencies utilized most by mysticetes (Hildebrand, 2009). Collecting auditory data on free-ranging mysticetes is exceptionally difficult, resulting in a considerable gap in knowledge surrounding the hearing thresholds of baleen whales (Clark et al., 2009). Using statistical models informed by the threshold shift conditions recorded in belugas, but with extensive sample variation and uncertainty analyses, Gedamke et al. (2011) assessed the potential damage seismic noise emissions have on mysticete hearing. Simulating a myriad of acoustic conditions demonstrated by seismic surveys, models suggested that baleen whales may experience the onset of temporary threshold shifts within $3 \mathrm{~dB}$ of the source levels demonstrated by belugas, between 180 and $186 \mathrm{~dB}$. However, the authors acknowledged that the findings of their study are speculative due to the dearth of empirical data regarding mysticete hearing.

\section{Sonar}

Sonar is an invaluable tool for the detection of objects below the sea surface. Utilized in military and civilian operations, active sonar systems emit acoustic pulses that are reflected by objects in the survey field, such as vessels, organisms, and bathymetric features. The reflected sounds can then be analyzed to determine the position and orientation of a detected 
object (NOAA, 2018b; Hildebrand, 2009). Mid-frequency sonars are used to map seafloor topography in addition to detecting free-moving objects. These arrays emit pulses that range in frequency from 1 to $12 \mathrm{kHz}$ with variable duration and sequence depending on their practical function (Hildebrand, 2009). Mid-frequency sonar from military vessels is typically horizontally emitted with a potential broadcast radius of $360^{\circ}$, in contrast to mapping vessels which propagate their acoustic signals down the water column (Hildebrand, 2009). Research vessels can use high-frequency sonar to detect individual organisms, aggregations, and scattering objects in the water column with relative precision. These arrays emit pulses at variable frequencies up to $1000 \mathrm{kHz}$, which can be used dynamically to distinguish between species occupying the same sampled water column and provide data relative to their biomass and distribution. Low-frequency active sonar usage is exclusive to a select few military vessels engaged in long-range scanning (Hildebrand, 2009). Due to their minimal attenuation in water, low-frequency acoustic pulses, ranging between 100 and $500 \mathrm{~Hz}$, can persist for hundreds of kilometers with relatively conserved sound pressures (Halvorsen et al., 2012). Sonar pulses are produced with high source levels between 200 and $245 \mathrm{~dB}$ across all frequency ranges (Hildebrand, 2009). Because of its many practical applications, sonar arrays are found on a significant proportion of seafaring vessels, both large and small, and are often operated continuously for navigation purposes, which suggests that sonar emissions are a persistent contributor to ambient noise in throughout the world (Hildebrand, 2009). 


\section{Behavior}

In most cases, active sonar systems produce sounds with source levels exceeding 200 $\mathrm{dB}$, well above detection threshold for cetaceans, however the lack of behavioral data for most species, as well as limitations in previous research, has created significant challenges in assessing the risks of sonar on broad scales (Miller et al., 2012). Miller et al. (2012) conducted field surveys of killer whales, sperm whales, and long-finned pilot whales exposed to sonar, incorporating observations of a wide range of potential response behaviors accounting for changes in foraging, traveling, and social interaction. The authors recorded peak source levels between 197 and $214 \mathrm{~dB}$ in low- and mid-frequency sonar sweeps, with some behavioral changes occurring at received sound pressure levels less than $110 \mathrm{~dB}$. Miller et al. (2012) found that the most common response to sonar exposure was avoidance, both horizontally and vertically, with considerable modifications to dive profile. Changes to vocal calling rates were noted in some groups, including reductions in echolocation sounds, indicating the cessation of foraging behaviors. Some groups of pilot whales formed tighter packs when exposed, and during one observation, engaged in synchronous surfacing behaviors within seconds of exposure to intense sonar source levels. While the exposure periods did not exceed 30 minutes of full-capacity sonar, the most severe response recorded was the separation of a killer whale calf from its group for hours following cessation of sonar production. The authors suggested that due to the timing of its separation, the calf may have detected the offending noise prior to peak levels being reached. While killer whales were shown to be particularly sensitive to midfrequency ( 6 to $7 \mathrm{kHz}$ ) sonar exposure, the sperm whales and pilot whales were more likely to respond to low-frequency sonar bands between $1 \mathrm{~Hz}$ and $2 \mathrm{kHz}$. The authors noted that of 
those behaviors recorded as "severe", many involve prolonged avoidance of the exposure area and foraging cessation, with potential costs to cetacean energy budgets and displacement.

Sivle et al. (2012) analyzed the dive profiles of the same three species as Miller et al. (2012) and found that killer whales and pilot whales spend most of their time near the surface, performing deeper dives up to $100 \mathrm{~m}$ and $600 \mathrm{~m}$, respectively, to forage. During these dives, the onset of sonar activities caused both species to abandon their depths and ascend to shallower waters. Sperm whales are known to forage at depths upwards of $1500 \mathrm{~m}$, rarely occupying waters above $20 \mathrm{~m}$, yet the authors did not observe similar abandonment of foraging depths in response to sonar. They did note, however, that the diving profiles of sperm whales exposed to sonar were shallower in comparison to controls, accompanied by a lack of vocal activity indicating the cessation of feeding activities. These findings were supported by Isojunno et al. (2016), which reported a significant reduction in foraging vocalizations coincident with low-frequency sonar exposure. Sivle et al. (2015) utilized the experimental design and behaviorresponse severity scale implemented by Miller et al (2012). to observe northern bottlenose whales, humpback whales, and minke whales exposed to sonar. The most severe behavioral responses were reported for bottlenose and minke whales, involving prolonged avoidance and foraging cessation, at relatively low thresholds, between 130 to $158 \mathrm{~dB}$. Humpback whales showed far fewer overt responses, but are believed to have higher detection thresholds than the other study cetaceans.

The effect that sonar has on the foraging behaviors of deep diving cetaceans may pose great risks for endangered species. Goldbogen et al. (2013) conducted a study on blue whales and produced the first observations of mid-frequency sonar sensitivity in baleen whales. With 
controlled-exposure experiments, the authors observed the responses to sonar exposure on foraging blue whales in deep-, shallow-, and non-feeding states. They found that, although surface-feeding blue whales were less likely to demonstrate a response, the deeper-feeding whales were more likely to cease foraging and the non-feeding whales, and showed tendency for midwater dives. One individual was predicted to be consuming $19 \mathrm{~kg}$ of krill per minute under normal conditions, but ceased foraging behaviors at the onset of sonar exposure for 62 minutes, constituting the loss of feeding potential upwards of one metric ton. The authors acknowledged the relatively common employment of mid-frequency sonar in the study region, due to prevalent naval activities, and suggested the possibility that some of the blue whales observed may have habituated to the noise input, implying a greater potential risk to unhabituated baleen whales.

\section{Deep-diving Cetaceans and Decompression Sickness}

Deep-diving whales, like the many species of beaked whales, face considerable challenges in managing their blood-gas volumes under the tremendous atmospheric pressure of the deep oceans (Hooker et al., 2012). When diving, dissolved gases move from the cardiovascular system into the surrounding tissues due to increasing hydrostatic pressure (Hooker et al., 2012). With rapid ascension, nitrogen gas becomes highly saturated in the tissues, disparate with the partial pressures present in the lungs, increasing the likelihood that these gases with form bubbles as they diffuse back into the bloodstream, resulting in decompression sickness (Hooker et al., 2012). Cetaceans manage their nitrogen gas loads while diving by minimizing oxygen consumption at depths through lung collapse and shunting blood 
away from non-critical tissues, in addition to controlling their ascension to allow for proper decompression (Hooker et al., 2012). However, evidence of decompression sickness appears in stranded deep-diving whales, which are capable of sequestering significant concentrations of nitrogen gas at great depths (Fernández et al., 2005; Hooker et al., 2012; Kvadsheim et al., 2012; Fahlman et al., 2014).

Kvadsheim et al. (2012) estimated the blood gas concentrations of five odontocete species, representing a range of body sizes and depth preferences, during exposure to low- and mid-frequency sonar. Across species, the common behavioral response to sonar emissions was cessation of depth foraging, resorting to shallower dives, with beaked whales exhibiting considerably slower ascension rates than demonstrated in meso- and epipelagic species. Estimates of end-dive nitrogen gas concentrations for the deep-divers, sperm whales and beaked whales, were significantly higher in comparison to shallow- and intermediate-divers, as would be expected considering the physiological impact of dive depth and duration. The ratio of end-dive nitrogen gas concentrations to ambient concentrations was designated by the authors as a coefficient of decompression sickness risk $(R)$, with high values indicative of the magnitude of dissolved gas supersaturation in tissues. Sperm whales and beaked whales exhibited higher relative $R$ values, but in some cases these values were far greater due to these animals spending more time in compression zones during sonar exposure, increasing the degree of supersaturation and thereby the risk of decompression sickness. The authors concluded by acknowledging that most cetacean behaviors will not incur physiological damage from noise sonar exposure, however deep-diving whales are more susceptible to 
decompression sickness due to the dive response, increasing the physiological risks of their behavioral responses to sonar with potentially fatal consequences.

\section{Mass Strandings}

In 2006, four Cuvier's beaked whales stranded on the Spanish coast of Almeria (Arbelo et al., 2008). After performing necropsies on the animals, Arbelo et al. (2008) reported no sign of disease, physical ailments, or pathogenic infection, but did find considerable evidence of venous gas emboli, including congestion and hemorrhage in the hearing structures and other

organs. Gas-bubble lesions, indicative of decompression sickness (Fernández et al., 2005), were also found in the vascular spaces of vital organs. Without any other physical or environmental cause implicated by the necropsies, the authors suggested that recent naval sonar activities instigated a severe behavioral response that caused decompression sickness in these whales, which may have initiated the subsequent strandings. A review by Filadelfo et al. (2008) found that five out of 14 cases of Cuvier's beaked whale mass strandings in the Mediterranean Sea and four out of seven strandings in the Bahamas, coincided with high-intensity naval sonar activities. Bootstrap analysis suggested that the likelihood of so many strandings occurring independently of the sonar emissions was less than $1 \%$.

With consideration of these stranding events, Tyack et al. (2011) took advantage of planned naval sonar exercises in the Bahamas to observe the behavioral responses of local foraging Blainville's beaked whales. Employing a large array of bottom-mounted hydrophones and satellite tags, the authors observed the change in echolocative "clicks" and lateral movement of the beaked whales before, during, and after sonar exposure. During exposure, 
beaked whales near the acoustic source ceased foraging and avoided the area, sometimes for prolonged periods. Sound pressure levels as low as $138 \mathrm{~dB}$ were observed eliciting behavioral change in the beaked whales, suggesting that beaked whales have greater sensitivities than wildlife regulations purport. McCarthy et al. (2011) published further analysis of the beaked whales studied by Tyack et al. (2011) supporting their observations of avoidance and behavior state, adding that the group vocal periods, the distinct sets of vocalization representative of a specific group of foraging whales, had failed to recover until 23 to 35 hours following the end of sonar activities. Cuvier's beaked whales in the waters of Southern California have also demonstrated behavioral responses to sonar exposure, ceasing vocal behaviors and rapidly increasing their distance from the source of noise, even under relatively low levels of received sound pressure (DeRuiter et al., 2013). Little is known about free-ranging beaked whales, however the considerable evidence suggesting sonar as a source of potential harm for these whales may also have greater implications for other deep-diving cetaceans (DeRuiter et al., 2013).

\section{Policy and Mitigation}

Anthropogenic noise is a dynamic and pervasive component of marine ecosystems. The specificity of impacts on both ecological and species-level scales, with consideration of unique bathymetric and acoustic interactions underwater, challenge the formation of comprehensive conservation strategies. Williams et al. (2015) highlighted the use of satellite vessel-tracking data to predict cumulative noise levels due to shipping traffic, which may identify acoustically threatened cetacean populations and indicate regions in need of regulation and mitigation. In 
this regard, marine spatial planning informed by vessel noise can furthermore identify acoustically pristine habitats ideal for the establishment of marine sanctuaries. Still, mitigating the noise emissions from vessel traffic is difficult to practically mitigate and is likely a permanent component of marine acoustic habitats (Erbe et al., 2012; Frisk, 2012; Williams et al., 2013).

For seismic noise and sonar, limited mitigation practices and conservation policies attempt to regulate noise impacts, including the common use of "ramp-up" and "soft-start" strategies that offer a warning to wildlife prior to full-scale deployment (Parsons et al., 2009; Wright \& Cosentino, 2015; Wensveen et al., 2017). Additionally, on-board observers are tasked with visually spotting whales within exclusion zones and signaling the cessation of noisegenerating activity to minimize their exposure to potentially damaging, high-intensity noise (Hildebrand, 2009). There is not enough data to suggest that these management strategies are successful at mitigating noise impacts on greater spatial or temporal scales, nor are they effective in every case, however they currently serve as the most practical method of reducing the risk of potential harm (Dunlop et al., 2016; Wensveen et al., 2017).

The UK's Joint Nature Conservation Committee (JNCC) was the first to institute guidelines for the minimization and mitigation of noise generated by seismic surveys and as such became the foundation for many international noise pollution policies (Parsons et al., 2009). In a critique of the JNCC guidelines, Parsons et al. (2009) noted significant regulatory issues in the planning stages of marine prospecting, identifying the complete lack of guidance from the JNCC with regards to data-deficient species or recommendations for conducting proper environmental impact assessments, potentially providing legal shelter for 
noncompliance. The authors also acknowledged a significant lag in data publication leading to policies informed by outdated information, further diminishing the efficacy of the JNCC regulations. Although the JNCC guidelines supply specific mitigation strategies, the authors noted inadequacies inherent in the Committee's assumptions regarding the behavior and acoustic sensitivities of cetaceans, the magnitude and impact zones of offending noise, as well as considerable issues regarding monitoring and compliance. Wright and Cosentino (2015) elaborated on the work done by Parsons et al. (2009) by including newly published works describing the non-injurious impacts of seismic noise. The authors determined that the JNCC guidelines contained very few considerations for the extensive temporal and spatial impacts of seismic noise, such as communication interference and migratory disruptions. Wright and Cosentino (2015) agreed with the previous assessments, suggesting that the JNCC guidelines needed significant improvements in management and regulatory strategies, as well as considerable updates to the scientific foundations of such strategies, in order to be effective at mitigating the broad-scale impacts of seismic noise on cetaceans.

Various European cetacean conservation agreements have sought to address impacts caused by sonar activities in the Mediterranean Sea, Baltic Sea, and the European Unioncontrolled Atlantic waters (Dolman et al., 2011). Dolman et al. (2011) suggested that some of the E.U. regulations contained considerations for deep-water noise impacts within sonar mitigation strategies and may be correlated with a decline in strandings for deep-diving species, such as beaked whales. The authors suggested that baseline data gaps and outdated environmental assessments were informing inadequate conservation policies, however they noted the greater challenge of ensuring the compliance of participating nation-states. Dolman 
et al (2011) acknowledged that many such large-scale conservation agreements are voluntary and exceedingly difficult to enforce, implying that diplomatic and political relations may have influenced more lenient regulations in order to ease their institution. Authors Zirbel et al. (2011) analyzed the legislation pertaining to sonar mitigation in the United States, finding that many of the regulations instituted to protect marine mammals and their habitats were attained by civil litigation of federal law. Various cases brought to the U.S. Supreme Court were largely responsible for defining the impact of sonar activities in American waters and the mitigation thereof, however the authors suggested that the courts regularly supported the priorities of the U. S. Navy and occasionally rejected evidence-based noise management strategies in favor of military preparedness. The authors highlighted the potential disadvantages of litigated conservation strategies, which required the watchful eyes and significant funding of NGOs to contend for environmentally ethical military and industrial practices. The legal cases reviewed by Zirbel et al. (2011) described several instances in which the US Navy failed to comply with federal laws in the planning of various naval sonar exercises. In multiple cases, it was the attentive work of civilian conservation agencies, such as the Natural Resources Defense Council, that discovered the malfeasance. These agencies often spearhead litigation in the U.S. high courts, invoking established legislation to halt environmentally harmful naval activities and enforce the necessary impact assessments and mitigation planning, which may have been otherwise disregarded. The U. S. Navy has repeatedly fought against certain sonar mitigation practices, such as greater zones of exclusion, contending that such regulation restricts the ability of the navy to properly train its fleet. Successful appeals of some mitigation parameters have established precedents in the high courts for the prioritization of national defense over 
environmental conservation, but Zirbel et al. (2011) suggested that the overall environmental impact of naval sonar exercises has been greatly reduced by dint of tenacious civil litigation.

\section{Discussion}

In their many ecological roles, cetaceans are marine ecosystem engineers (Roman et al., 2014). As apex predators and often keystone species, cetaceans exert top-down control across all trophic levels and stabilize trophic interactions from the sea surface to the deep oceans. They are important to nutrient and carbon flux in the oceans in that they consume tremendous quantities of organic compounds and redistribute them throughout the water column through their waste and in death (Roman et al., 2014). Their long lives, low reproductive rates, and persistence in human-mediated environments, in addition to occupying the highest trophic levels, enable many cetacean species to serve as sentinels for marine ecosystem health (Bossart, 2011). The world's oceans are exhibiting unprecedented change in the $21^{\text {st }}$ Century, with human impacts implicated in global-scale shifts in marine geochemical, biological, and ecological profiles (Giorgi et al., 2001; Harwood, 2001; Orr et al., 2005; Bossart, 2011). Cetacean bioacoustic research has demonstrated that whales are dynamic vocalists and powerful communicators with highly-developed acoustic capabilities provided by extreme anatomical adaptations (Payne \& Webb, 1971; Di Sciara \& Gordon, 1997; Smith et al., 2008; Branstetter et al., 2017a; Branstetter et al., 2017b) and as such are justifiably sensitive to noise pollution in their habitats (Williams et al., 2013). Consider again the North Atlantic right whales, inhabiting waters besieged by human activities. Although greatly impacted by ship strikes, chemical pollutants, and anthropogenic interactions affecting prey availability, the measures taken thus 
far to manage such impacts predicted a rate of recovery that has not been observed (Kraus et al., 2012). Until 2012, few had considered the potential physiological harm of anthropogenic noise as many of the biologically significant impacts suggested by researchers were largely speculative. In presenting the first evidence of a physiological stress response in right whales to vessel noise, Rolland et al. (2012) justified the consideration of anthropogenic noise as a pernicious threat to cetacean biology. Attempts at generalizing the effects of anthropogenic noise pollution have been reductive, as acoustic interactions and responses will vary between individuals, populations, species, and regions (Hildebrand, 2009). Quantifying the cumulative impact of anthropogenic noise on cetacean species and habitats is likely an impossible task, considering the overwhelming difficulties inherent to cetacean research and the acceleration of climate change-driven habitat degradation (Harwood, 2001; NRC, 2003; Bossart, 2011; Frisk, 2012). It is, however, evident that the long-term conservation of cetacean species must incorporate management of environmental noise pollution and will require multivariate assessments of specific regions and populations to inform meaningful policy (Simmonds et al., 2014; Williams et al., 2015; Kunc et al., 2016). It is unknown whether the efforts made to recover the North Atlantic right whale will be enough to prevent their extinction. Significant shifts in prey availability, increasing injurious vessel and fisheries interactions, and exposure to pathogens and chemical pollutants are jeopardizing right whale recruitment and survivorship, further increasing the likelihood of extinction (Bossart, 2011; Meyer-Gutbrod \& Greene, 2018). Like most environmental pollutants, anthropogenic noise cannot be eliminated without the unconditional removal of human activity from the world's oceans (Hildebrand, 2009). Nonetheless, understanding the range and magnitude of noise impacts on cetaceans will be 
necessary to ensure that conservation strategies can support the recovery and long-term health of vulnerable populations, and do more than just stave off decline (Southall et al., 2009;

Williams et al., 2013; Meyer-Gutbrod \& Greene, 2018; Bossart, 2011;). 


\section{Bibliography}

Annotations italicized

\section{Works Cited}

Arbelo, M., de Quiros, Y. B., Sierra, E., Méndez, M., Godinho, A., Ramírez, G., ... Fernández, A. (2008). Atypical beaked whale mass stranding in Almeria's coast: Pathological study. Bioacoustics, 17 (1-3), 295-297.

Ashe, E., Noren, D. P., \& Williams, R. (2010). Animal behavior and marine protected areas: incorporating behavioural into the selection of marine protected areas for an endangered killer whale population. Animal Conservation, 13 (2), 196-203.

Bassett, C., Polagye, B., Holt, M., \& Thomson, J. (2012). A vessel noise budget for Admiralty Inlet, Puget Sound, Washington (USA). The Journal of the Acoustical Society of America, 132(6), 37063719.

Blair, H. B., Merchant, N. D., Friedlaender, A. S., Wiley, D. N., \& Parks, S. E. (2016). Evidence for ship noise impacts on humpback whale foraging behaviour. Biology Letters, 12(8).

Bossart, G. D. (2011). Marine Mammals as Sentinel Species for Oceans and Human Health. Veterinary Pathology, 48(3), 676-690.

Branstetter, B. K., St Leger, J., Acton, D., Stewart, J., Houser, D., Finneran, J. J., \& Jenkins, K. (2017a). Killer whale (Orcinus orca) behavioral audiograms. The Journal of the Acoustical Society of America, 141(4), 2387-2398.

Branstetter, B. K., Van Alstyne, K. R., Wu, T. A., Simmons, R. A., Curtis, L. D., \& Xitco, M. J. (2017b). Composite critical ratio functions for odontocete cetaceans. The Journal of the Acoustical Society of America, 142(4), 1897-1900. 
Castellote, M., Clark, C. W., \& Lammers, M. O. (2012). Acoustic and behavioural changes by fin whales (Balaenoptera physalus) in response to shipping and airgun noise. Biological Conservation, 147(1), 115-122.

Clark, C. W., Ellison, W. T., Southall, B. L., Hatch, L., Van Parijs, S. M., Frankel, A., \& Ponirakis, D. (2009). Acoustic masking in marine ecosystems: intuitions, analysis, and implication. Marine Ecology Progress Series, 395, 201-222.

Deecke, V. B., Barrett-Lennard, L. G., Spong, P., \& Ford, J. K. B. (2010). The structure of stereotyped calls reflects kinship and social affiliation in resident killer whales Orcinus orca. Naturwissenschaften, 97(5), 513-518.

DeRuiter, S. L., Southall, B. L., Calambokidis, J., Zimmer, W. M. X., Sadykova, D., Falcone, E. A., ... Tyack, P. L. (2013). First direct measurements of behavioural responses by Cuvier's beaked whales to mid-frequency active sonar. Biology Letters, 9(4), 20130223.

Di lorio, L., \& Clark, C. W. (2010). Exposure to seismic survey alters blue whale acoustic communication. Biology Letters, 6(1), 51-54.

Di Sciara, G. N., \& Gordon, J. (1997). Bioacoustics: A tool for the conservation of cetaceans in the Mediterranean Sea. Marine and Freshwater Behaviour and Physiology, 30(2), 125-146.

Dolman, S. J., Evans, P. G. H., Di Sciara, G. H., \& Frisch, H. (2011). Active sonar, beaked whales and European regional policy. Marine Pollution Bulletin, 63(1), 27-34.

Dunlop, R. A., Noad, M. J., McCauley, R. D., Kniest, E., Paton, D., \& Cato, D. H. (2015). The Behavioural Response of Humpback Whales (Megaptera novaeangliae) to a 20 Cubic Inch Air Gun. Aquatic Mammals, 41, 412-433. 
Dunlop, R. A. (2016). The effect of vessel noise on humpback whale, Megaptera novaeangliae, communication behaviour. Animal Behaviour, 111, 13-21.

Dunlop, R. A., Noad, M. J., McCauley, R. D., Kniest, E., Slade, R., Paton, D., \& Cato, D. H. (2016). Response of humpback whales (Megaptera novaeangliae) to ramp-up of a small experimental air gun array. Marine Pollution Bulletin, 103(1), 72-83.

Acoustic communication in humpback whales is critical to the species survival, but background noise in their environment has the capacity to mask biologically significant signals. Responses to noise effects on communication include increasing the source level of their signals, duration, and frequencies of the sounds produced. Vessel noise frequencies overlap those of many baleen whale sounds, to which some cetacean species have been known to demonstrate the aforementioned responses. However, natural background noise, such as that caused by wind, can also interfere with communication, and in this case humpback whales have been known to switch to nonvocal communication, such as fin slapping. Previous work regarding anthropogenic noise has rarely put cetacean responses in context with natural sources of noise. This study tests a hypothesis that predicts humpback whales responding to vessel noise in the same stereotyped manner by which they respond to wind noise. In humpbacks, vocal source levels increased as wind noise increased, but did not increase further with increasing vessel noise. There was no evidence to suggest that the whales changed the frequency or duration of sounds with increased background noise. Because the whales did not increase or change the source levels or types of calls made, it is likely that communication is significantly masked in high noise environments, which may have deleterious effects on reproductive success. It is possible too that the strategies 
used to cope with natural noise are ineffective after a certain point when coping with anthropogenic noise

Dunlop, R. A., Noad, M. J., McCauley, R. D., Scott-Hayward, L., Kniest, E., Slade, R., ... Cato, D. H. (2017a). Determining the behavioural dose-response relationship of marine mammals to air gun noise and source proximity. Journal of Experimental Biology, 220(16), 2878-2886.

Seismic airgun arrays produce intense pulses of sound that penetrate the seabed in order to locate resources such as oil and gas. Seismic surveys can occur over long periods of time, up to 24 hours a day for months, with large arrays of 20+ guns firing at intervals of 8-15 seconds. Large whale responses to airgun arrays is context and behavior dependent. This study aims to quantify the response of migrating humpback whales relative to baseline behavior and to assess the biological significance of the responses. No abnormal behaviors were observed and thus no evidence was found to suggest that the airgun arrays elicited a biologically significant response with stress impacts. Groups of migrating whales responded to the seismic survey with changes in the magnitude and rate of movement, dive patterns, and breaching behaviors and a significant reduction in migration progression compared to baseline behavior was noted.

Dunlop, R. A., Noad, M. J., McCauley, R. D., Kniest, E., Slade, R., Paton, D., \& Cato, D. H. (2017b). The behavioural response of migrating humpback whales to a full seismic airgun array. Proceedings. Biological Sciences, 284(1869).

Dyndo, M., Wiśniewska, D. M., Rojano-Doñate, L., \& Madsen, P. T. (2015). Harbour porpoises react to low levels of high frequency vessel noise. Scientific Reports, 5. 11083. Vessel noise has been recently reported to contribute medium and high frequency noise to marine habitats, to the detriment of odontocetes, who are otherwise protected from the 
majority low-frequency noise commonly associated with ships. Dyndo, et. al, stereotyped behaviors related to vessel noise exposure observed in P. phocoena. 4 individuals maintained in a net pen, reactions were categorized as porpoising or not porpoising. The porpoises, despite being habituated to the known noisy environment, reacted to $30 \%$ of vessels from which noise was detected. The paper provides physiological implications, as well as policy guidelines relative to the sensitivities recorded and projected by the research.

EPA (2017). Southern Resident Killer Whales [Reports and Assessments]. Retrieved May 3, 2018, from https://www.epa.gov/salish-sea/southern-resident-killer-whales

Erbe, C., MacGillivray, A., \& Williams, R. (2012). Mapping cumulative noise from shipping to inform marine spatial planning. The Journal of the Acoustical Society of America, 132(5), 423-428.

Fahlman, A., Tyack, P. L., Miller, P. J. O., \& Kvadsheim, P. H. (2014). How man-made interference might cause gas bubble emboli in deep diving whales. Frontiers in Physiology, 5.

Fernández, A., Edwards, J. F., Rodríguez, F., Espinosa de los Monteros, A., Herráez, P., Castro, P., ... Arbelo, M. (2005). "Gas and fat embolic syndrome" involving a mass stranding of beaked whales (family Ziphiidae) exposed to anthropogenic sonar signals. Veterinary Pathology, 42(4), 446-457.

Filadelfo, R., Mintz, J., Michlovich, E., D’Amico, A., Tyack, P. L., \& Ketten, D. R. (2009). Correlating Military Sonar Use with Beaked Whale Mass Strandings: What Do the Historical Data Show? Aquatic Mammals, 35(4), 435-444.

Frisk, G. V. (2012). Noiseonomics: The relationship between ambient noise levels in the sea and global economic trends. Scientific Reports, 2, 437. 
Gedamke, J., Gales, N., \& Frydman, S. (2011). Assessing risk of baleen whale hearing loss from seismic surveys: The effect of uncertainty and individual variation. The Journal of the Acoustical Society of America, 129(1), 496-506.

Gervaise, C., Simard, Y., Roy, N., Kinda, B., \& Ménard, N. (2012). Shipping noise in whale habitat: Characteristics, sources, budget, and impact on belugas in Saguenay-St. Lawrence Marine Park hub. The Journal of the Acoustical Society of America, 132(1), 76-89.

Giorgi, F., Dahl, P. H., Jones, R. G., Christensen, J. H., Mearns, L. O., Hewitson, B. R., ... Jack, C. (2001). Emerging patterns of simulated regional climatic changes for the 21st century due to anthropogenic forcings. Geophysical Research Letters, 28(17), 3317-3320.

Goldbogen, J. A., Southall, B. L., DeRuiter, S. L., Calambokidis, J., Friedlaender, A. S., Hazen, E. L., ... Tyack, P. L. (2013). Blue whales respond to simulated mid-frequency military sonar. Proc. R. Soc. B, 280(1765), 20130657.

Halvorsen, M. B., Zeddies, D. G., Ellison, W. T., Chicoine, D. R., \& Popper, A. N. (2012). Effects of midfrequency active sonar on hearing in fish. The Journal of the Acoustical Society of America, 131(1), 599-607.

Harwood, J. (2001). Marine mammals and their environment in the twenty-first century. Journal of Mammalogy, 82(3), 630-640.

Harwood, L. A., Smith, T. G., Joynt, A., Kennedy, D., Pitt, R., Moore, S., \& Millman, P. (2010). Displacement of whales and seals by seismic and exploratory drilling in the Canadian Beaufort Sea. Presented at the Canada-United States Northern Oil and Gas Research Forum, Calgary, CA. 
Hatch, L. T., Clark, C. W., Van Parijs, S. M., Frankel, A. S., \& Ponirakis, D. W. (2012). Quantifying Loss of Acoustic Communication Space for Right Whales in and around a U.S. National Marine Sanctuary. Conservation Biology, 26(6), 983-994.

Heide-Jørgensen, M. P., Hansen, R. G., Westdal, K., Reeves, R. R., \& Mosbech, A. (2013). Narwhals and seismic exploration: Is seismic noise increasing the risk of ice entrapments? Biological Conservation, 158, 50-54.

Hermannsen, L., Tougaard, J., Beedholm, K., Nabe-Nielsen, J., \& Madsen, P. T. (2015). Characteristics and propagation of airgun pulses in shallow water with implications for effects on small marine mammals. PLOS ONE, 10(7), 1-17.

Hildebrand, J. A. (2009). Anthropogenic and natural sources of ambient noise in the ocean. Marine Ecology Progress Series, 395, 5-20.

Holt, M. M., Noren, D. P., \& Emmons, C. K. (2011). Effects of noise levels and call types on the source levels of killer whale calls. The Journal of the Acoustical Society of America, 130(5), 3100-3106. Killer whales utilize a variety of call types for foraging, navigation, and social interactions, with many call type repertoires being unique to populations or specific groups. Some calls have a high frequency component (HFC) that is thought to be important to group orientation and coordination. Calls with high source levels, such as HFC calls, may be a response to higher levels of background environmental noise. Southern Resident Killer Whales are exposed to greater levels of shipping traffic and noise than their northern counterparts. In comparing the average source levels of different call types between the two populations, it was found that the southern residents increased their call amplitudes in response to higher levels of noise and those calls with HFCs demonstrated higher source levels. Higher source levels seem to correlate with 
expansion of active communication space within killer whale pods, and under increased noise conditions may have reduced efficacy and limit group interactions.

Hooker, S. K., Fahlman, A., Moore, M. J., Soto, N. A., de Quirós, Y. B., Brubakk, A. O., ... Tyack, P. L. (2012). Deadly diving? Physiological and behavioural management of decompression stress in diving mammals. Proc. R. Soc. B, 279(1731), 1041-1050.

Hunt, K. E., Lysiak, N. S., Moore, M., \& Rolland, R. M. (2017). Multi-year longitudinal profiles of cortisol and corticosterone recovered from baleen of North Atlantic right whales (Eubalaena glacialis). General and Comparative Endocrinology, 254, 50-59.

Isojunno, S., Curé, C., Kvadsheim, P. H., Lam, F.-P. A., Tyack, P. L., Wensveen, P. J., \& Miller, P. J. O. (2016). Sperm whales reduce foraging effort during exposure to $1-2 \mathrm{kHz}$ sonar and killer whale sounds. Ecological Applications, 26(1), 77-93.

Jensen, F., Bejder, L., Wahlberg, M., Aguilar de Soto, N., Johnson, M., \& Madsen, P. (2009). Vessel noise effects on delphinid communication. Marine Ecology Progress Series, 395, 161-175.

Kamminga, C. (1988). Echolocation Signal Types of Odontocetes. In Animal Sonar (pp. 9-22). Springer, Boston, MA.

Kastelein, R., Helder-Hoek, L., Van de Voorde, S., von Benda-Beckmann, S., Lam, F.-P., Jansen, E., ... Ainslie, M. (2017). Temporary hearing threshold shift in a harbor porpoise (Phocoena phocoena) after exposure to multiple airgun sounds. The Journal of the Acoustical Society of America, 142(4), 2430-2442.

Ketten, D. R. (1992). The Marine Mammal Ear: Specializations for Aquatic Audition and Echolocation. In The Evolutionary Biology of Hearing (pp. 717-750). Springer, New York, NY.

Ketten, D. R. (1997). Structure and Function in Whale Ears. Bioacoustics, 8(1-2), 103-135. 
Ketten, D. R. (2002). Marine Mammal Auditory Systems: A summary of audiometric and anatomical data and implications for underwater acoustic impacts. Polarforschung, 72(2/3), 79-92.

Koopman, H. N., Budge, S. M., Ketten, D. R., \& Iverson, S. J. (2006). Topographical distribution of lipids inside the mandibular fat bodies of odontocetes: remarkable complexity and consistency. IEEE Journal of Oceanic Engineering, 31(1), 95-106.

Kraus, S. D., Kenney, R. D., Mayo, C. A., Mclellan, W. A., Moore, M. J., \& Nowacek, D. P. (2016). Recent Scientific Publications Cast Doubt on North Atlantic Right Whale Future. Frontiers in Marine Science, 3.

Kunc, H. P., McLaughlin, K. E., \& Schmidt, R. (2016). Aquatic noise pollution: implications for individuals, populations, and ecosystems. Proceedings of the Royal Society B: Biological Sciences, 283(1836).

Kvadsheim, P. H., Miller, P. J. O., Tyack, P. L., Sivle, L. L. D., Lam, F.-P. A., \& Fahlman, A. (2012). Estimated tissue and blood N2 levels and risk of in vivo bubble formation in deep-, intermediate- and shallow diving toothed whales during exposure to naval sonar. Frontiers in Physiology, 3.

La Manna, G., Manghi, M., Pavan, G., Lo Mascolo, F., \& Sarà, G. (2013). Behavioural strategy of common bottlenose dolphins (Tursiops truncatus) in response to different kinds of boats in the waters of Lampedusa Island (Italy). Aquatic Conservation: Marine and Freshwater Ecosystems, 23(5), 745-757.

Lucke, K., Siebert, U., Lepper, P. A., \& Blanchet, M.-A. (2009). Temporary shift in masked hearing thresholds in a harbor porpoise (Phocoena phocoena) after exposure to seismic airgun stimuli. The Journal of the Acoustical Society of America, 125(6), 4060-4070. 
Lusseau, D., Bail, D. E., Williams, R., \& Smith, J. C. (2009). Vessel traffic disrupts the foraging behavior of southern resident killer whales Orcinus orca. Endangered Species Research, 6, 211-221.

McCarthy, E., Moretti, D., Thomas, L., DiMarzio, N., Morrissey, R., Jarvis, S., ... Dilley, A. (2011). Changes in spatial and temporal distribution and vocal behavior of Blainville's beaked whales (Mesoplodon densirostris) during multiship exercises with mid-frequency sonar. Marine Mammal Science, 27(3), 206-226.

Meyer-Gutbrod, E. L., \& Greene, C. H. (2018). Uncertain recovery of the North Atlantic right whale in a changing ocean. Global Change Biology, 24(1), 455-464.

Miller, P. J. O., Kvadsheim, P. H., Lam, F. A., Wensveen, P. J., Antunes, R., Alves, A. C., ... Sivle, L. D. (2012). The Severity of behavioral changes observed during experimental exposures of killer (Orcinus orca), long-finned Pilot (Globicephala melas), and sperm (Physeter macrocephalus) whales to naval sonar. Aquatic Mammals, 38(4), 362-401.

Mitson, R. B. (1995). Underwater noise of research vessels: Review and recommendations (ICES Cooperative Research Report No. 209) (p. 61). Denmark: International Council for the Exploration of the Sea.

MMC (2018). Human-Caused Mortality and Injury to the North Atlantic Right Whale. Retrieved April 16, 2018, from https://www.mmc.gov/priority-topics/species-of-concern/north-atlantic-rightwhale/human-caused-mortality-injury-north-atlantic-right-whale/

Moholkar, V. S., \& Pandit, A. B. (2004). Bubble behavior in hydrodynamic cavitation: Effect of turbulence. AIChE Journal, 43(6), 1641-1648.

Mooney, W. D., \& Brocher, T. M. (2010). Coincident seismic reflection/refraction studies of the continental lithosphere: A global review. Reviews of Geophysics, 25(4), 723-742. 
Moore, J. E., \& Barlow, J. P. (2013). Declining Abundance of Beaked Whales (Family Ziphiidae) in the California Current Large Marine Ecosystem. PLOS ONE, 8(1), e52770.

Moore, S. E., Reeves, R. R., Southall, B. L., Ragen, T. J., Suydam, R. S., \& Clark, C. W. (2012a). A New Framework for Assessing the Effects of Anthropogenic Sound on Marine Mammals in a Rapidly Changing Arctic. BioScience, 62(3), 289-295.

Moore, S. E., Stafford, K. M., Melling, H., Berchok, C., Wiig, Ø., Kovacs, K. M., ... Richter-Menge, J. (2012b). Comparing marine mammal acoustic habitats in Atlantic and Pacific sectors of the High Arctic: year-long records from Fram Strait and the Chukchi Plateau. Polar Biology, 35(3), 475480.

NOAA (2014). NOAA Draft Guidance for Assessing Effects of Anthropogenic Sound on Marine Mammals: Acoustic Threshold Levels for Onset of Permanent and Temporary Threshold Shifts. Retrieved from http://www.nmfs.noaa.gov/pr/acoustics/publicmeeting2014_presentation.pdf NOAA (2018a). Marine Mammal Acoustic Thresholds. Retrieved June 5, 2018, from http://www.westcoast.fisheries.noaa.gov/protected species/marine mammals/threshold gui dance.html

NOAA (2018b). What is sonar? Retrieved April 22, 2018, from https://oceanservice.noaa.gov/facts/sonar.html

Norman, S. A., Hobbs, R. K. C., Goertz, C. E. C., Burek-Huntington, K. A., Shelden, K. E. W., Smith, W. A., \& Beckett, L. A. (2015). Potential Natural and Anthropogenic Impediments to the Conservation and Recovery of Cook Inlet Beluga Whales, Delphinapterus leucas. Marine Fisheries Review, 77(2), 89-105. 
NRC (2000). Marine Mammals and Low-Frequency Sound: Progress Since 1994 (Committee to Review Results of ATOC's Marine Mammal Research Program). National Academies Press (US). NRC (2003). Ocean Noise and Marine Mammals. National Academies Press (US).

NRC (2018). 2017-2018 North Atlantic Right Whale Unusual Mortality Event. Retrieved April 11, 2018, from /national/marine-life-distress/2017-2018-north-atlantic-right-whale-unusual$\underline{\text { mortality-event }}$

Orr, J. C., Fabry, V. J., Aumont, O., Bopp, L., Doney, S. C., Feely, R. A., ... Yool, A. (2005). Anthropogenic ocean acidification over the twenty-first century and its impact on calcifying organisms. Nature, 437(7059), 681-686.

Papale, E., Gamba, M., Perez-Gil, M., Martin, V. M., \& Giacoma, C. (2015). Dolphins adjust speciesspecific frequency parameters to compensate for increasing background noise. PLOS ONE, 10(4).

Parsons, E. C. M., Dolman, S. J., Jasny, M., Rose, N. A., Simmonds, M. P., \& Wright, A. J. (2009). A critique of the UK's JNCC seismic survey guidelines for minimising acoustic disturbance to marine mammals: Best practise? Marine Pollution Bulletin, 58(5), 643-651. The Joint Nature Conservation Committee established guidelines in 1995 for the mitigation of seismic noise on marine mammals. First in its class, the JNCC guidelines quickly became the standard of future management strategies. However, little of the JNCC practices have strong empirical backing, with weaknesses identified in planning strategies and ineffectual data. JNCC recommends review of literature in the planning stages of seismic surveys to identify vulnerable species of marine mammals in the projected sites, however there is scant available data for most affected species and no guidelines from the JNCC for how to proceed with baseline data 
gaps. JNCC guidelines makes few recommendations for the legal aspect of protected species management, with only loose guidelines to avoid breeding or calving periods. The zone of impact established by the JNCC is arbitrarily defined as 500m from the source. Mitigation strategies within this zone include "ramp-up" periods in which sound from the arrays is systematically increased to serve a warning to animals in the area. Evidence suggests that received noise levels can be significant up to $9 \mathrm{~km}$ and the simple spreading law of sound by which the guideline was established is not sufficient for management. If an animal is observed in the zone of impact during the ramp-up period, JNCC guidelines insist that the survey must be delayed until the animal has moved outside of the zone. However, the forced shut down of acoustic disturbance is not obligatory or enforceable. Human observation has extreme limitations due to environmental conditions, marine mammal surfacing behavior, and human error. Observers may also lack necessary experience to effectively serve. JNCC guidelines also lack considerations in the number of airguns used in seismic arrays as well as oceanographic effects that interact with sound propagation, such as temperature and salinity.

Payne, R., \& Webb, D. (1971). Orientation by means of long range acoustic signaling in baleen whales. Annals: New York Academy of Sciences, 188, 110-142.

Pirotta, E., Milor, R., Quick, N., Moretti, D., Marzio, N. D., Tyack, P., ... Hastie, G. (2012). Vessel Noise Affects Beaked Whale Behavior: Results of a Dedicated Acoustic Response Study. PLOS ONE, 7(8), e42535.

Reeves, R. R., Ewins, P. J., Agbayani, S., Heide-Jørgensen, M. P., Kovacs, K. M., Lydersen, C., ... Blijleven, R. (2014). Distribution of endemic cetaceans in relation to hydrocarbon development and commercial shipping in a warming Arctic. Marine Policy, 44, 375-389. 
Ritts, M. (2017). Amplifying environmental politics: Ocean noise. Antipode, 49(5), 1406-1426.

Rolland, R. M., Parks, S. E., Hunt, K. E., Castellote, M., Corkeron, P. J., Nowacek, D. P., ... Kraus, S. D. (2012). Evidence that ship noise increases stress in right whales. Proceedings of the Royal Society B: Biological Sciences, 279(1737), 2363-2368.

Increased low frequency vessel noise have the potential to mask biologically significant sounds that right whales rely on to communicate, forage, and court mates. Immediately following the events of 9/11, vessel traffic in the Bay of Fundy, a critical habitat of North Atlantic Right Whales with the highest levels of background low-frequency noise, decreased significantly and the requisite decrease in noise produced in these high traffic waters provided a unique environment to observe physiological changes in right whales under diminished noise conditions. Fecal samples were analyzed for hormone metabolites and glucocorticoids as a measure of physiological stress. This study shows a decrease in baseline concentrations of fGCs correlated with a $6 d B$ reduction in noise levels and significant decrease in low frequency noise. No other identified factors are believed to explain this relationship. "Chronic elevations of GCs secondary to repeated or continuous stressors become maladaptive, suppressing growth, immune system function, and reproduction." Even with compelling evidence, definitively linking stress to health in free swimming large whales is extremely difficult, the authors recognize limitations in their sample and scale, as well as lack of controls.

Roman, J., Estes, J. A., Morissette, L., Smith, C., Costa, D., McCarthy, D., ... Smetacek, V. (2014). Whales as marine ecosystem engineers. Frontiers in Ecology and the Environment, 12(7), 377385. 
Simmonds, M. P., Dolman, S. J., Jasny, M., Parsons, E. C. M., \& Weilgart, L. (2014). Marine Noise Pollution - Increasing Recognition But Need for More Practical Action. Journal of Ocean Technology, 9(1), 71-90.

Sivle, L. D., Kvadsheim, P. H., Fahlman, A., Lam, F.-P., Tyack, P., \& Miller, P. J. O. (2012). Changes in dive behavior during naval sonar exposure in killer whales, long-finned pilot whales, and sperm whales. Frontiers in Physiology, 3, 400.

Sivle, L., Kvadsheim, P. H., Curé, C., Isojunno, S., Wensveen, P., Lam, F.-P., ... Miller, P. J. O. (2015). Severity of Expert-Identified Behavioural Responses of Humpback Whale, Mike Whale, and Northern Bottlenose Whale to Naval Sonar. Aquatic Mammals, 41, 469-502.

Small, R. J., Brost, B., Hooten, M., Castellote, M., \& Mondragon, J. (2017). Potential for spatial displacement of Cook Inlet beluga whales by anthropogenic noise in critical habitat. Endangered Species Research, 32, 43-57.

Smith, J. N., Goldizen, A. W., Dunlop, R. A., \& Noad, M. J. (2008). Songs of male humpback whales, Megaptera novaeangliae, are involved in intersexual interactions. Animal Behaviour, 76(2), 467-477.

Southall, B. L., Bowles, A. E., Ellison, W. T., Finneran, J. J., Gentry, R. L., Greene, C. R., ... Tyack, P. L. (2009). Marine mammal noise exposure criteria: Initial scientific recommendations. The Journal of the Acoustical Society of America, 125(4), 2517-2517.

Stamation, K. A., Croft, D. B., Shaughnessy, P. D., Waples, K. A., \& Briggs, S. V. (2010). Behavioral responses of humpback whales (Megaptera novaeangliae) to whale-watching vessels on the southeastern coast of Australia. Marine Mammal Science, 26(1), 98-122. 
Tyack, P. L., Zimmer, W. M. X., Moretti, D., Southall, B. L., Claridge, D. E., Durban, J. W., ... Boyd, I. L. (2011). Beaked Whales Respond to Simulated and Actual Navy Sonar. PLOS ONE, 6(3), e17009. Veirs, S., Veirs, V., \& Wood, J. D. (2016). Ship noise extends to frequencies used for echolocation by endangered killer whales. PeerJ, 4, e1657.

Wartzok, D., \& Ketten, D. R. (1999). Marine Mammal Sensory Systems. In Biology of Marine Mammals (Vol. 1, pp. 117-175). Smithsonian Institution Press.

Weglein, A. B., Araújo, F. V., Carvalho, P. M., Stolt, R. H., Matson, K. H., Coates, R. T., ... Zhang, H. (2003). Inverse scattering series and seismic exploration. Inverse Problems, 19(6), R27.

Weilgart, L. S. (2007). The impacts of anthropogenic ocean noise on cetaceans and implications for management. Canadian Journal of Zoology, 85(11), 1091-1116.

Weintraub, K. (2018). No Sign of Newborn North Atlantic Whales This Breeding Season. The New York Times.

Weir, C. (2008). Overt Responses of Humpback Whales (Megaptera novaeangliae), Sperm Whales (Physeter macrocephalus), and Atlantic Spotted Dolphins (Stenella frontalis) to Seismic Exploration off Angola. Aquatic Mammals, 34 (1), 71-83.

Weir, C. R., \& Dolman, S. J. (2007). Comparative review of the regional marine mammal mitigation guidelines implemented during industrial seismic surveys, and guidance towards a worldwide standard. Journal of International Wildlife Law and Policy, 10 (1), 1-27.

Wensveen, P. J., Kvadsheim, P. H., Lam, F.-P. A., von Benda-Beckmann, A. M., Sivle, L. D., Visser, F., ... Miller, P. J. O. (2017). Lack of behavioural responses of humpback whales (Megaptera novaeangliae) indicate limited effectiveness of sonar mitigation. Journal of Experimental Biology, 220(22), 4150-4161. 
Wieland, M., Jones, A., \& Renn, S. C. P. (2010). Changing durations of southern resident killer whale (Orcinus orca) discrete calls between two periods spanning 28 years. Marine Mammal Science, 26(1), 195-201.

Williams, R., Clark, C. W., Ponirakis, D., \& Ashe, E. (2013). Acoustic quality of critical habitats for three threatened whale populations. Animal Conservation, 17(2), 174-185.

Williams, R., Wright, A. J., Ashe, E., Blight, L. K., Bruintjes, R., Canessa, R., ... Wale, M. A. (2015). Impacts of anthropogenic noise on marine life: Publication patterns, new discoveries, and future directions in research and management. Ocean \& Coastal Management, 115, 17-24. Apart from shipping noise, offshore seismic surveys, pile-driving construction, and military activity are likely to contribute greatly to local and regional noise levels. Since its identification as a pollutant in 1971 (Payne and Webb), anthropogenic noise research, especially of the marine variety, has grown and diversified, with exponential growth in the discipline and discourse community since 2010. This paper highlights 6 ongoing projects that represent the state of ocean noise scholarship and management strategies, as well as an analysis of publication and research trends. In the Strait of Georgia, BC, a critical habitat for endangered killer whale ecotypes and their acoustically receptive prey, is an extremely high traffic waterway leading to one of the busiest shipping ports in North America. Combining acoustic data and AIS ship tracking, it is possible to create an AIS-based prediction model of the noise exposure in the waterway; $91 \%$ of the noise detected was attributable to AIS-tracked ships and fell within a specific frequency range. Sound exposure maps could help identify both areas of harmful noise exposure and noise refuges. Discussion surrounding AIS-driven modelling points out a lack of detail in vessel tracking that limits the effectiveness of such noise models. Current AIS 
technology cannot account for the high volumes of small watercraft which may contribute significantly to habitat noise levels. Chronic ocean noise in vulnerable whale habitats poses challenges to management and policy strategies. Noise mitigation policies attempt to operationalize harm limits and reduction techniques that have weak empirical support. Current challenges include the dearth of research regarding cumulative impacts on vulnerable populations and a lack of species-level data and audiograms that validate generalized harm limits. Publication of noise-based research has traditionally been supported in acoustic and engineering journals but is now seeing much greater representation in biological and ecological publications, with marine mammals representing the greatest proportion of biological subjects.

Winsor, M. H., Irvine, L. M., \& Mate, B. R. (2017). Analysis of the spatial distribution of satellitetagged sperm whales (Physeter macrocephalus) in close proximity to seismic surveys in the Gulf of Mexico. Aquatic Mammals, 43(4), 439-446.

Wisniewska, D. M., Johnson, M., Teilmann, J., Siebert, U., Galatius, A., Dietz, R., \& Madsen, P. T. (2018). High rates of vessel noise disrupt foraging in wild harbour porpoises (Phocoena phocoena). Proc. R. Soc. B, 285(1872), 2017-2314.

Wittekind, D., \& Schuster, M. (2016). Propeller cavitation noise and background noise in the sea. Ocean Engineering, 120, 116-121.

Wright, A. J., \& Cosentino, A. M. (2015). JNCC guidelines for minimising the risk of injury and disturbance to marine mammals from seismic surveys: We can do better. Marine Pollution Bulletin, 100(1), 231-239.

Zirbel, K., Balint, P., \& Parsons, E. C. M. (2011). Navy sonar, cetaceans and the US Supreme Court: A review of cetacean mitigation and litigation in the US. Marine Pollution Bulletin, 63(1), 40-48. 


\section{Additional References}

Chapman, N. R., \& Price, A. (2011). Low frequency deep ocean ambient noise trend in the Northeast Pacific Ocean. The Journal of the Acoustical Society of America, 129(5), EL161-EL165.

Corcoran, M. B. (2014). U.S. Navy Sonar and Marine Mammals: A Recommendation of Additional Marine Mammal Mitigation Measures in the Northwest Testing and Training (NWTT) Study Area (Thesis).

De Robertis, A., Wilson, C. D., Furnish, S. R., \& Dahl, P. H. (2013). Underwater radiated noise measurements of a noise-reduced fisheries research vessel. ICES Journal of Marine Science, 70(2), 480-484.

Dolman, S. J., \& Jasny, M. (2015). Evolution of Marine Noise Pollution Management. Aquatic Mammals; Moline, 41(4), 357-374.

Dunlop, R. A., Cato, D. H., \& Noad, M. J. (2010). Your attention please: increasing ambient noise levels elicits a change in communication behaviour in humpback whales (Megaptera novaeangliae). Proceedings of the Royal Society of London B: Biological Sciences, 277(1693), 2521-2529.

Dunlop, R. A., Noad, M. J., McCauley, R. D., Kniest, E., Slade, R., Paton, D., \& Cato, D. H. (2016). Response of humpback whales (Megaptera novaeangliae) to ramp-up of a small experimental air gun array. Marine Pollution Bulletin, 103(1), 72-83.

Finneran, J. J. (2015). Noise-induced hearing loss in marine mammals: A review of temporary threshold shift studies from 1996 to 2015. The Journal of the Acoustical Society of America, 138(3), 1702-1726. 
Gomez, C., Lawson, J. W., Wright, A. J., Buren, A. D., Tollit, D., \& Lesage, V. (2016). A systematic review on the behavioural responses of wild marine mammals to noise: the disparity between science and policy. Canadian Journal of Zoology, 94(12), 801-819.

Guan, S., Vignola, J., Judge, J., \& Turo, D. (2015). Airgun inter-pulse noise field during a seismic survey in an Arctic ultra-shallow marine environment. The Journal of the Acoustical Society of America, 138(6), 3447-3457.

Harris, C. M., Thomas, L., Falcone, E. A., Hildebrand, J., Houser, D., Kvadsheim, P. H., ... Janik, V. M. (2017). Marine mammals and sonar: Dose-response studies, the risk-disturbance hypothesis and the role of exposure context. Journal of Applied Ecology, 55(1), 396-404.

Hatch, L., Clark, C., Merrick, R., Parijs, S. V., Ponirakis, D., Schwehr, K., ... Wiley, D. (2008). Characterizing the Relative Contributions of Large Vessels to Total Ocean Noise Fields: A Case Study Using the Gerry E. Studds Stellwagen Bank National Marine Sanctuary. Environmental Management, 42(5), 735-752.

Holt, M. M., Noren, D. P., Veirs, V., Emmons, C. K., \& Veirs, S. (2008). Speaking up: Killer whales (Orcinus orca) increase their call amplitude in response to vessel noise. The Journal of the Acoustical Society of America, 125(1), EL27-EL32.

Mann, D., Hill-Cook, M., Manire, C., Greenhow, D., Montie, E., Powell, J., ... Hoetjes, P. (2010). Hearing Loss in Stranded Odontocete Dolphins and Whales. PLOS ONE, 5(11), e13824.

Markus, T., \& Sánchez, P. P. S. (2018). Managing and Regulating Underwater Noise Pollution. In Handbook on Marine Environment Protection (pp. 971-995). Springer.

McKenna, M. F., Ross, D., Wiggins, S. M., \& Hildebrand, J. A. (2012). Underwater radiated noise from modern commercial ships. The Journal of the Acoustical Society of America, 131(1), 92-103. 
Mooney, T. A., Nachtigall, P. E., \& Vlachos, S. (2009). Sonar-induced temporary hearing loss in dolphins. Biology Letters, 5(4), 565-567.

Morton, A. B., \& Symonds, H. K. (2002). Displacement of Orcinus orca by high amplitude sound in British Columbia, Canada. ICES Journal of Marine Sciences, 59, 71-80.

Noren, D. P., Johnson, A. H., Rehder, D., \& Larson, A. (2009). Close approaches by vessels elicit surface active behaviors by southern resident killer whales. Endangered Species Research, 8(3), 179-192.

Nowacek, D. P., Clark, C. W., Mann, D., Miller, P. J., Rosenbaum, H. C., Golden, J. S., ... Southall, B. L. (2015). Marine seismic surveys and ocean noise: time for coordinated and prudent planning. Frontiers in Ecology and the Environment, 13(7), 378-386.

Parks, S. E., Johnson, M., Nowacek, D., \& Tyack, P. L. (2011). Individual right whales call louder in increased environmental noise. Biology Letters, 7(1), 33-35.

Rutenko, A. N., \& Ushchipovskii, V. G. (2015). Estimates of acoustic noise generated by supply vessels working with oil-drilling platforms. Acoustical Physics, 61(5), 556-563.

Saxon-Kendall, L., \& Cornick, L. (2016). Behavior and distribution of Cook Inlet beluga whales, Delphinapterus leucas, before and during pile driving activity. Marine Fisheries Review, 77, 106114.

Cook Inlet is a critical migratory route for a declining population of belugas, leading to feeding grounds and nursery waters. Coastal development along the inlet has produced significant noise, with special attention given to pile-driving construction practices. Previous research showed that belugas change vocal activity in the presence of pile driving; this study observed beluga behavior during two periods of pile driving activity. Results reported a $54 \%$ reduction in 
surface sighting duration and $67 \%$ increase in traveling behaviors. There was an observed increase in diving behaviors without typical foraging behaviors engaged, an increase in densely packed groupings, an increase in lone juvenile whales, and a reduction in mean group size. All behaviors observed are suggested to be implicit response to pile driving noise. The paper provides negative ecological implications of such behavioral responses.

Stimpert, A. K., DeRuiter, S. L., Southall, B. L., Moretti, D. J., Falcone, E. A., Goldbogen, J. A., ... Calambokidis, J. (2014). Acoustic and foraging behavior of a Baird's beaked whale, Berardius bairdii, exposed to simulated sonar. Scientific Reports, 4, 7031.

Stimpert, et. al, present the first data on acoustic foraging behavior in B. bairdii and observations of response to simulated sonar noise. The researchers tagged an individual Baird's beaked whale a multi-sensor tag. During sound exposure, the whale's dive patterns changed, often with vertical direction reversal. Analysis identified a response period beginning 3.1 mins after the onset of noise and continuing 1.6 mins after sound production had ceased. The whale also tended to increase its swimming speed in response. Analysis of the aural thresholds for this species is not available, but this research suggests that B. bairdii is likely to have significant sensitivity to anthropogenic noise.

Tournadre J. (2014). Anthropogenic pressure on the open ocean: The growth of ship traffic revealed by altimeter data analysis. Geophysical Research Letters, 41(22), 7924-7932.

Williams, R., Lusseau, D., \& Hammond, P. S. (2006). Estimating relative energetic costs of human disturbance to killer whales (Orcinus orca). Biological Conservation, 133(3), 301-311. 
Yamato, M., Khidas, K., Pyenson, N. D., Fordyce, R. E., \& Mead, J. G. (2016). Extensively remodeled, fractured cetacean tympanic bullae show that whales can survive traumatic injury to the ears. Journal of Anatomy, 228(1), 125-136.

Surveying museum collections, the authors discovered 11 new specimens of fractured and/or healed cetacean ear bones, largely from species for which no such data exists. The odontocete specimens displayed less healing, and it may be possible that either the trauma which caused the fractures contributed to the individual's death or that hearing damage is more lethal to echolocative species. Bone complex structure is a contingency of proper hearing in whales, thus all specimens were likely to have experienced significant hearing loss. The authors contend that the force of blunt trauma necessary to cause the observed damage to tympanic bullae would be fatal, and suggest that external pressure waves caused by underwater detonations. Reproductive females may be more susceptible to damage due to calcium depletion. 